\title{
Dietary mineral supplies in Malawi: spatial and socioeconomic assessment
}

\author{
Edward J. M. Joy ${ }^{1,2+}{ }^{1}$, Diriba B. Kumssa ${ }^{1,2,3+}{ }^{2}$, Martin R. Broadley ${ }^{1}$, Michael J. Watts ${ }^{2}$, Scott D. Young ${ }^{1}$, \\ Allan D. C. Chilimba ${ }^{4}$ and E. Louise Ander ${ }^{2 *}$
}

\begin{abstract}
Background: Dietary mineral deficiencies are widespread globally causing a large disease burden. However, estimates of deficiency prevalence are often only available at national scales or for small population sub-groups with limited relevance for policy makers.

Methods: This study combines food supply data from the Third Integrated Household Survey of Malawi with locally-generated food crop composition data to derive estimates of dietary mineral supplies and prevalence of inadequate intakes in Malawi.

Results: We estimate that $>50 \%$ of households in Malawi are at risk of energy, calcium (Ca), selenium (Se) and/or zinc $(\mathrm{Zn})$ deficiencies due to inadequate dietary supplies, but supplies of iron $(\mathrm{Fe})$, copper $(\mathrm{Cu})$ and magnesium $(\mathrm{Mg})$ are adequate for $>80 \%$ of households. Adequacy of iodine $(\mathrm{I})$ is contingent on the use of iodised salt with $<1 \%$ of households getting adequate I supply from food alone. Hidden hunger is likely to be widespread: among households with adequate energy supply, 30, 56 and $27 \%$ had inadequate supplies of Ca, Se and Zn, respectively. Over $80 \%$ of the poorest households had inadequate dietary supplies of Ca and $\mathrm{Zn}$ compared to $<30 \%$ of the wealthiest households; $>80 \%$ of rural households living on low-pH soils had inadequate dietary Se supplies compared to $55 \%$ on calcareous soils; concurrent inadequate supplies of Ca, Se and Zn were observed in >80\% of the poorest rural households living in areas with non-calcareous soils. Prevalence of inadequate dietary supplies was greater in rural than urban households for all nutrients except Fe. Interventions to address dietary mineral deficiencies were assessed. For example, an agronomic biofortification strategy could reduce the prevalence of inadequate dietary Se supplies from 82 to $14 \%$ of households living in areas with low-pH soils, including from 95 to $21 \%$ for the poorest subset of those households. If currently-used fertiliser alone were enriched with Se then the prevalence of inadequate supplies would fall from 82 to $57 \%$ with a cost per alleviated case of dietary Se deficiency of $\sim$ US\$ 0.36 year $^{-1}$.
\end{abstract}

Conclusions: Household surveys can provide useful insights into the prevalence and underlying causes of dietary mineral deficiencies, allowing disaggregation by spatial and socioeconomic criteria. Furthermore, impacts of potential interventions can be modelled.

Keywords: Dietary mineral deficiencies, Household survey, Malawi, Micronutrient supplies, Spatial

\footnotetext{
* Correspondence: land@bgs.ac.uk

${ }^{\dagger}$ Equal contributors

${ }^{2}$ Inorganic Geochemistry, Centre for Environmental Geochemistry, British

Geological Survey, Keyworth, Nottingham NG12 5GG, UK

Full list of author information is available at the end of the article
} 


\section{Background}

Food security is defined as having access to sufficient, safe and nutritious food to meet the needs of an active and healthy life [1]. Food insecurity can manifest as 'hunger' due to inadequate dietary energy intake, or 'hidden hunger', due to deficiencies of vitamins and mineral elements. Hidden hunger is widespread globally with an estimated two billion people at risk of vitamin $\mathrm{A}$, iron (Fe), iodine (I) and zinc ( $\mathrm{Zn}$ ) deficiencies, causing a considerable social and economic burden particularly in low-income countries including sub-Saharan Africa [2-10]. Deficiencies of other vitamins and elements are also likely to be widespread globally, including selenium (Se) which shows significant spatial variation due to environmental factors [11-14].

The prevalence of vitamin or element deficiencies can be quantified through analysis of their concentrations in blood plasma, other tissues or urine; however, conducting wide-scale surveys can be expensive and logistically challenging. In addition, some biomarkers might not be sufficiently accurate or sensitive indicators of deficiency, particularly for mild deficiencies, e.g. for $\mathrm{Zn} \mathrm{[15].} \mathrm{In}$ certain cases, health outcomes can be a useful proxy to measure prevalence of dietary nutrient deficiencies, for example stunting as an indicator of $\mathrm{Zn}$ deficiency [16]. However, such relationships can be confounded by environmental factors or multiple causes of the same health outcome and surveys of health outcomes remain expensive and logistically challenging to conduct. Thus, dietary assessment can be a useful approach whereby the mass of an element consumed or supplied in the diet is quantified, either through direct analysis of composite diets or through matching of food intake records and relevant composition data. Following conventional terminology, 'inadequate dietary supply' of a micronutrient puts an individual 'at risk of deficiency' where deficiency causes negative health outcomes. There are a number of factors that may confound the relationship between 'dietary intakes' and 'nutritional sufficiency', such as nutrientnutrient interactions, impaired gut absorption or increased losses of vitamins and elements due to infection. For example, phytic acid (PA) is the principal form of phosphorus in cereal grains and inhibits the absorption of $\mathrm{Fe}, \mathrm{Mg}$ and $\mathrm{Zn}$ in the human gut [17].

Previously, the prevalence of micronutrient deficiencies or inadequate dietary supplies in Malawi have been reported using different methods (c.f. Table 1 of Joy et al. [18] for a summary). Anthropometric measures and dietary recall matched to local or regional food composition data were used to quantify dietary supplies and deficiency prevalence of micronutrients in sub-national populations [19-25]. Global, regional or national estimates of deficiency risks were generated using food supply data captured in Food Balance
Sheets (FBSs) published by the United Nations Food and Agriculture Organization [9, 13, 18, 22, 26, 27], or consumption data captured in national Household Surveys [28-30]. These studies have shown or estimated that deficiencies of calcium $(\mathrm{Ca})$, I and $\mathrm{Zn}$ are likely to be widespread in Malawi due to inadequate dietary supplies whereas dietary supplies of copper $\mathrm{Cu}$ ) and magnesium $(\mathrm{Mg})$ appear to be adequate for those with sufficient dietary energy intake. Some studies report generally adequate dietary supplies of Fe and low prevalence of Fe-deficiency anaemia [9, 18, 25], while others report generally inadequate dietary Fe supplies and high prevalence of Fe-deficiency anaemia [24, 30], and this requires further study. Spatial variation in crop composition due to soil type is an important determinant of dietary supplies of some elements; for example, a high prevalence of Se deficiency is likely among populations living on low-pH soils but not on calcareous soils with $\mathrm{pH}>6.5$ [22].

The present study considers both environmental and socioeconomic determinants of dietary element supplies in Malawi. Household dietary energy, PA, Ca, Cu, Fe, I, $\mathrm{Mg}$, Se and $\mathrm{Zn}$ supplies were quantified by integrating datasets for food consumption, food composition and nutrient requirements. Results were aggregated by defining household characteristics, e.g. urban/rural location, at national and Extension Planning Area (EPA) levels. The EPA is an administrative unit of the Ministry of Agriculture and Food Security. There are 186 EPAs in Malawi with mean and median land areas of 49,600 and 38,900 ha, respectively. Typically, an EPA office will have a good working knowledge of the local area and maintain contact with a high proportion of member households. Thus, EPAs provide an effective network through which agriculture-nutrition interventions can be implemented, especially given that $85 \%$ of the population are involved in agriculture, predominantly subsistence production [31].

\section{Methods \\ Food consumption}

Household food consumption and socioeconomic data were derived from the Third Malawi Integrated Household Survey (IHS3) in which a nationally-representative sample of 12,271 households were interviewed during March 2010-March 2011 [28]. These data were obtained by the authors as fully anonymised secondary data from the World Bank open-data repository [32]. Author use of this open-data archive is compliant with requirements of World Bank, as specified upon data retrieval through the data portal [32]. In the first stage of household selection, Enumeration Areas (EAs) were chosen at random to represent Districts; the probability of EA selection was proportional to the number of member households. 
In the second stage of selection, 16 households were selected at random to represent each EA with five replacement households in case of failure to complete the interview process. On average, EPAs were represented by 4.3 EAs (range 1-28) [33].

In the food consumption module, interviewees were asked to recall the food consumed in the household during the past 7 days from a list of 112 food items (e.g. 'Maize ufa refined (fine flour)', 'Dried fish', etc.). Enumerators recorded the source of the food item (i.e. 'own production', 'bought' or 'gift') and the amount consumed. Interviewees could choose from a selection of units that included standard metric measures (grams, litres etc.) and local units (small plate, large plate, small bucket, large bucket, basin etc.) to assist in estimating the quantity consumed.

There were some inexplicit food categories (e.g. 'Other cultivated green leafy vegetables'); these items were matched to a generic crop in this study (e.g. 'Cabbage leaf') unless enumerators provided a more specific description (e.g. 'Other cultivated green leafy vegetables Bonongwe', meaning leaf of Amaranthus spp.), in which case new item codes were assigned to match more appropriate crop composition data. In total, $>99 \%$ of food records were decipherable and were included. To calculate mass consumed, local units were converted into metric units; this was done on an item-specific basis because of the variation in density of food items. The IHS3 team measured the mass of local units of common food items from 48 retail markets in Malawi and report a conversion table by region (north, central and south). However, there are still many data gaps in the published conversion table. In addition, some of the conversion factors given vary widely between regions with no apparent explanation; for example, the mass of unit 'Pail (small)' for food item 'Maize ufa refined (fine flour)' is reported as 1.83, 5.02 and $3.11 \mathrm{~kg}$ in north, central and south regions, respectively. Therefore the conversion table was re-constructed using author judgement and was applied independent of region (Additional file 1: Table S1). The inedible portions of food items (e.g. banana skin, maize cob) were estimated using author judgement (Additional file 1: Table S2). The unit/mass conversion table, inedible proportion and moisture content data (see below) were used to estimate daily household (hh) consumption of the edible portion (EP) of food items on a dry-weight (DW) basis (i.e. $\mathrm{kg} \mathrm{hh}^{-1} \mathrm{~d}^{-1}$, DW EP).

Inspection of the raw survey data revealed some implausible entries. For example, 145 households were recorded as consuming $>1 \mathrm{~kg}$ capita ${ }^{-1} \mathrm{~d}^{-1}$ of the food item 'Maize ufa refined (fine flour)'. To mitigate such potential entry errors, a maximum plausible daily consumption of each food item was imposed; this affected just $1459(<1 \%)$ out of a total of $>197,000$ food entries (Additional file 1: Table S3).

\section{Nutrient composition}

Food items in the IHS3 were matched to food crop samples from a previous national survey of plant elemental concentrations [18]. Survey samples were pooled by species and tissue, for example 'Mango_fruit', 'Cassava_leaf' or 'Cassava_root', and were assigned to one of three composition tables according to the soil type at sampling location: 'calcareous', 'non-calcareous' and 'undifferentiated' (i.e. independent of soil type; Fig. 1; Additional file 1: Table S4 and Additional file 1: Table S5) [18]. Further food composition data generated since the publication of earlier findings are included in this study and are highlighted in Additional file 1: Table S5. These include nine fish samples collected at lakeshore and inland markets, comprising both small fish (usipa and kapenta) which are typically eaten whole, and larger fish (matemba, chambo, utake and mbalule) which are typically gutted before cooking with the meat, small bones and head all consumed but larger bones discarded. The consumption of whole fish

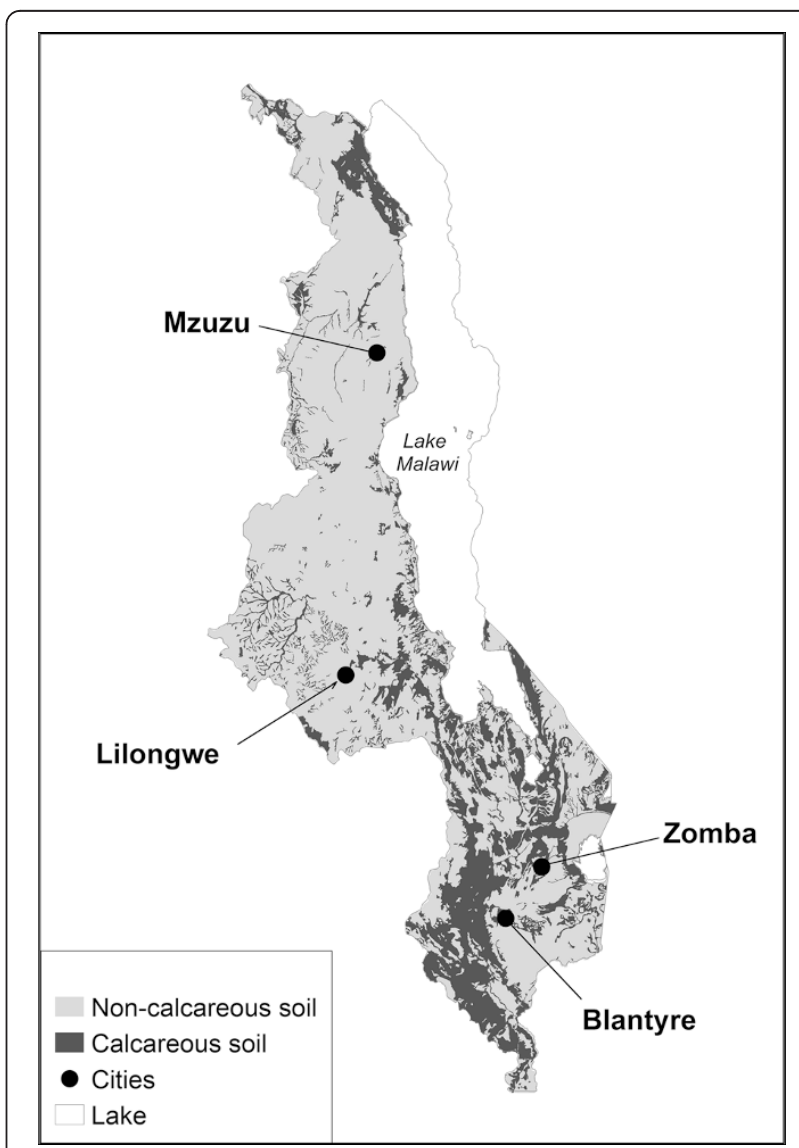

Fig. 1 Soils of Malawi. Soils are classified as calcareous or non-calcareous. Soil series mapping from [43] 
including bones is likely to be a significant source of dietary $\mathrm{Ca}$ intake, yet the IHS3 questionnaire did not specify the size of fish consumed so mineral composition data for all fish samples were combined into one category which was not stratified by soil class. Rice samples were also not stratified by soil class as, unlike other grains or fresh crops, rice is mainly grown along the lakeshore and in the Shire River basin and is frequently traded over long distances in Malawi. For example, among rural households, 73, 15 and $12 \%$ of rice consumption entries in IHS3 came from purchases, own production and gifts, respectively, compared to 38, 57 and $5 \%$, respectively, for refined maize flour. Thus for rice, the soil type at household, market or mill sampling site is unlikely to be a good predictor of the soil type on which it was grown.

The influence of outlying composition data was minimised by using median concentrations of plant/tissue groupings; however, as some sample sizes were very small (e.g. three samples of 'Pumpkin_fruit' from calcareous soils), data were screened for evidence of extraneous contamination that might make composition data unrepresentative of what is eaten. Plausible maximal elemental concentrations of plant tissues were derived from the plant nutrition literature, e.g. 500 and $100 \mathrm{mg} \mathrm{kg}^{-1}$ of $\mathrm{Cu}$ in leaf and seed, and $100 \mathrm{mg} \mathrm{kg}^{-1}$ of $\mathrm{Zn}$ in seed and fruit $[34,35]$. Thus, seven and four $\mathrm{Cu}$ and $\mathrm{Zn}$ data points, respectively, were excluded. Concentrations of aluminium, titanium and vanadium in these samples did not show evidence of contamination with soil dust so elevated $\mathrm{Cu}$ and $\mathrm{Zn}$ concentrations were likely due to sample preparation methods including cutting and blending samples with metal blades and were deemed unlikely to be representative of foods eaten in Malawi (Additional file 1: Table S5). One sample of tomato fruit had a high $\mathrm{Cu}$ concentration (sample number 13380-0002, $190.2 \mathrm{mg} \mathrm{kg}^{-1} \mathrm{DW}$ ) but was not excluded as $\mathrm{Cu}$-based fungicides are commonly used on tomato plants in Malawi, especially during the rainy season when this sample was collected, and this $\mathrm{Cu}$ concentration may be representative of what is eaten.

The staple dish nsima is prepared using maize flour ( $u f a$ ), using either refined or whole grain. To make refined flour, grain is winnowed, de-hulled, soaked in water for $\sim 3 \mathrm{~d}$, dried in the sun and then milled. Of the 12,271 households with food consumption records, $\sim 10,000$ reported consuming maize flour of which 6000 consumed 'Maize ufa refined (fine flour)' with mean consumption of $276 \mathrm{~g}$ capita ${ }^{-1} \mathrm{~d}^{-1}$. However, inadequate samples of refined flour were collected during the survey of plant crop elemental concentrations to provide reliable composition data for this important food item. Therefore, composition data for whole maize grain was used, adjusted by a standard ratio for the effects of processing on elemental concentrations. The standard ratio was calculated from paired whole grain and refined maize flour samples collected at maize mills (Additional file 1: Table S6). Consumption of whole grain maize flour, i.e. the food item 'Maize ufa mgaiwa (normal flour)', was recorded by $\sim 6000$ households with mean consumption of $249 \mathrm{~g}_{\text {capita }}^{-1} \mathrm{~d}^{-1}$; maize grain composition data without any conversion factor was matched to this food item.

Where relevant composition data were not available (including for most animal products and for energy and PA), suitable matches were established using published food composition tables, primarily Tanzania [36] and the USA [37] (Additional file 1: Table S4). Composition data from published sources were converted to DW concentrations using matched moisture content data (Additional file 1: Table S4). The concentration of PA is greater in the bran than the endosperm of maize grain and milling and processing typically reduces PA concentrations, e.g. from 880 down to $234 \mathrm{mg} 100 \mathrm{~g}^{-1}$ DW [19]. Thus, the reported PA concentration of $800 \mathrm{mg}$ $100 \mathrm{~g} \mathrm{~g}^{-1}$ edible portion of maize flour [36] is likely to represent whole grain flour. To avoid over-estimating the supply of PA from food items made with refined cereal flours, a $75 \%$ reduction in PA concentration was assumed due to milling and processing (Additional file 1: Table S7).

\section{Nutrient requirements}

Household demographic information was used to calculate the dietary nutrient requirements of households. For calorie requirements, Dietary Energy Requirements (DERs) recommended by the FAO were used [38]. All individuals were assumed to lead a moderately active to active lifestyle with physical activity level (PAL) of 1.9 and mean body mass for adult males and females was assumed to be 70 and $65 \mathrm{~kg}$, respectively (this is revisited in the Discussion). Estimated Average Requirements (EARs) and Recommended Nutrient Intakes (RNIs) for $\mathrm{Ca}, \mathrm{Fe}, \mathrm{I}, \mathrm{Mg}$ and $\mathrm{Zn}$ were obtained from the World Health Organization (WHO) [39] as these data are likely to be suitable for non-U.S. population groups. The EAR and RNI define intake levels adequate for 50 and $97.5 \%$, respectively, of healthy individuals in an age and sexspecific population group. The WHO does not provide requirement data for $\mathrm{Cu}$, so these were obtained from the Institute of Medicine [40]. The US/IOM values were also used for Se, e.g. adult $E A R=45 \mu \mathrm{g} \mathrm{d}^{-1}$ [41], because WHO recommendations for Se intake, e.g. adult male $E A R=28 \mu \mathrm{g} \mathrm{d}^{-1}$ [39], are probably too low based on recent evidence [14].

Module D of the IHS3 provides the opportunity for pregnancy of household members to be recorded under the section 'illness or injury'. Only 21 instances of pregnancy were recorded from 12,842 women aged 15-49 
included in the survey. Conversely, the total fertility rate in Malawi during 2005-10 was 5.83 [42] which would translate to $\sim 1650$ instances of pregnancy; thus data capture appears to be incomplete. Lactation status was also not captured, so fertility rates by five-year age group for 2010 were used to estimate the proportion of women who were pregnant or lactating and to make an adjustment to nutrient requirements to account for their greater requirements. For example, the EARs of $\mathrm{Zn}$ for women aged 15-19 years are 12.0, 14.0 and $15.0 \mathrm{mg} \mathrm{d}^{-1}$ for non-pregnant, pregnant and lactating individuals, respectively [39]. In Malawi in 2010, 11 and $14 \%$ of women aged 15-19 were estimated to be pregnant and lactating, respectively. Therefore, the adopted EAR for all 15-19 year old women in the IHS3 was $12.6 \mathrm{mg} \mathrm{d}^{-1}$.

\section{Data integration}

Data were integrated in a database (Microsoft Access 2010, Microsoft Corporation, Redmond, WA, USA). Statistical analyses were carried out using MINITAB (Version 15, Minitab Corporation, Pennsylvania, USA), 'R' (Version 3.0.2, R Foundation for Statistical Computing, Vienna, Austria) and GenStat (Version 17, VSN International, Hemel Hempstead, UK). Spatial data management and analyses were conducted using ArcGIS (Version 10.2.1, ESRI, Redlands, CA, USA).

Food composition tables developed for 'calcareous', 'non-calcareous' or 'undifferentiated' soil types were applied to households depending on their location. Exact Geographical Position System (GPS) locations of the households are not available in the public domain to protect confidentiality of the respondents [28]. The data field which provides the greatest spatial resolution is the administrative unit Enumeration Area (EA). The IHS3 sampled 768 EAs with mean and median land areas of 1748 and 745 ha, respectively. A single GPS point is reported in the survey to represent all households within an EA. The point was formed by taking the average latitude and longitude of all households in an EA followed by a displacement (for data protection reasons) of $0-2 \mathrm{~km}$ in urban EAs and $0-10 \mathrm{~km}$ in rural area EAs to create a modified location within the original EA [28]. The modified EA point locations were overlaid with the EA polygons as per the 1998 Malawi population census (latest publicly available GIS data) to provide polygon spatial data for each EA; this was spatially overlaid with a soil map of Malawi [43] using the intersection function in ArcGIS to extract the proportion of each EA covered by calcareous and non-calcareous soils.

Food consumption of households in rural areas was matched to either 'calcareous' or 'non-calcareous' food composition data depending on the soils in the EA; EA soil class was assigned as 'calcareous' or 'non-calcareous' if more than two-thirds of the area was covered by one of these soil classes (Additional file 1: Table S8). Some soils are likely to be unsuitable for agricultural production, for example mountainous terrain with minimal or zero soil depth or marsh land that frequently floods, and these were omitted from the calculation of area by soil class. If there was no dominant soil class then the 'undifferentiated' food composition table was adopted. A total of 13 EAs in the survey had a land area $\geq 10,000$ ha. These large EAs included National Parks and other sparsely populated areas and a more accurate prediction of the soil type on which households were located was determined by laying a $5 \mathrm{~km}$ buffer around the aggregated household EA GPS point. The soil class was then determined by calculating the proportion of calcareous and non-calcareous soils within the buffer (example map provided in Additional file 2: Figure S1). For urban EAs, the 'undifferentiated' food composition table was adopted as household location is unlikely to be a good predictor of the soil type on which their food was grown.

Households were eliminated if energy consumption was implausible, defined as $>8000$ or $<400 \mathrm{kcal}$ per Adult Male Equivalent (AME) $\mathrm{d}^{-1}$, thus eliminating 154 out of 12,271 households to leave 12,117 households. The AME is a unit based on the ratio of energy requirement between an individual and the benchmark of an adult male aged 18-30 with a PAL of 1.75 , i.e. $2800 \mathrm{kcal}[38,44]$. For example, a household with one adult male, one adult female, a 4-year-old daughter and a 1-year-old son would have an AME value of $\sim 3$. The effect of more stringent exclusion criteria is explored in the Discussion.

\section{Estimates of nutrient supplies and prevalence of inadequate intakes}

Food consumption $\left(\mathrm{kg}^{-1} \mathrm{hh}^{-1} \mathrm{~d}^{-1}\right.$, DW EP) and food composition data (mg kg ${ }^{-1}$, DW EP) were combined to calculate the supply of each nutrient at the household level. While the unit of analysis remains the household, supply per capita was calculated for each household as this provides a tangible metric that allows comparison with previously published estimates. In addition, household demographic composition was used to calculate supply per AME for each household. Supply per AME is a preferable metric when comparing households with different age or gender compositions and is used for comparing household supplies within the present study, e.g. between poorer and wealthier households.

The contribution of food groups to nutrient supplies was quantified by assigning food items to the following groups: 'Animal products', 'Cereals', 'Fats and oils', 'Fish', 'Fruits', 'Legumes', 'Milk products', 'Roots and tubers', 'Vegetables' and 'Others' (Additional file 1: Table S4). Nutrient supplies from each food group were summed for a defined set of households, and were divided by the sum of nutrient supplies from all food groups. 
The prevalence of inadequate intakes was estimated at the household level by comparing dietary element supplies with the combined EAR or RNI of all household members. Adequacy of household $\mathrm{Zn}$ supply was further characterised by the dietary PA:Zn molar ratio, where a value $>15$ is considered to provide inadequate bioavailable $\mathrm{Zn}$ [17].

\section{Results}

\section{Household characteristics}

Food consumption and household characteristics were recorded for 12,271 households in the IHS3 with a combined occupancy of $\sim 56,000$ individuals. A total of 154 households were found to consume unrealistic amounts of energy and were excluded from further analysis. A summary of the socioeconomic and environmental characteristics of the remaining 12,117 households is provided in Additional file 1: Table S9, with the relationships between characteristics provided in Additional file 1: Table S10 and Additional file 1: Table S11. More rural households (9944) were interviewed than urban (2173) while the number of households interviewed by expenditure quintile ranged from 1840 to 3191 in quintiles 1 (poorest) and 5 (wealthiest). Expenditure quintiles were delimited based on per capita consumption expenditure. Mean household size was 5.8, 5.2, 4.8, 4.3 and 3.6 for expenditure quintiles 1 to 5 , respectively. Thus, although the number of interviewed households varied between expenditure quintiles, the number of individuals covered in each expenditure quintile was equivalent. The number of rural households located on non-calcareous and calcareous soils was 6523 and 2047, respectively, while 1374 were not assigned to a particular soil type. The 179 EPAs were represented by varying numbers of households, e.g. from 15 in Chileka to 431 in Ntonda, with varying socioeconomic and environmental characteristics, e.g. median expenditure quintile 1 in Dolo to 5 in seven of the EPAs (Additional file 1: Table S12).

\section{Foods consumed}

Interviewees were asked to recall foods consumed over the past 7 days. Maize is the dominant staple crop of Malawi and 11,704 households (97 \%) consumed either refined or whole grain maize flour while 3815 (31 \%) consumed rice (Additional file 1: Table S13). Median consumption of maize flour per AME was $320 \mathrm{~g} \mathrm{DW} \mathrm{d}^{-1}$. Only 408 households consumed sorghum and 264 consumed either pearl or finger millet. 5263 households (43\%) consumed cassava (either as a boiled root or flour), 4664 consumed sweet potato (orange or white) and 2018 consumed potato (Additional file 1: Table S13).

A total of 10,529 households (87\%) consumed some form of animal product (meat, fish, eggs or milk) during the 7 day recall period, with 9286 (79\%) consuming fish.
Dried fish were particularly popular with 7935 households consuming this item and median consumption per AME of $17 \mathrm{~g} \mathrm{DW} \mathrm{d}^{-1}$ (Additional file 1: Table S13). Fish consumption (yes/no) was related to household expenditure quintile (Pearson Chi-square $=652$, $\mathrm{df}=4$, $p<0.001$; Fig. 2), with greater consumption in wealthier and urban households (Additional file 1: Table S14).

Interviews were conducted from March 2010 to March 2011 inclusive, each month was represented by $\geq 527$ interviews. The climate of Malawi is characterised by one rainy season, generally lasting from November to February in the Southern region and December to April in the Central and Northern regions. The mid-rainy season is sometimes referred to as the 'hunger gap' as cereal crops have not matured and last season's household stores are depleted. Over $75 \%$ of households reported consuming the item 'Green Maize' (i.e. fresh cob, boiled) in March, but $<15 \%$ in May-December. Overall, cereal consumption showed no marked seasonal variation suggesting that stocks from the 2009 and 2010 harvests were adequate for most households or were covered by increased purchases or gifts (Fig. 2; Additional file 1: Table S15). The 2009/10 growing season was favourable in Northern and Central regions and produced a national surplus of maize [45]. However, there were prolonged dry spells in parts of the Southern region which reduced crop yields [45]. Despite this, there was no evidence of seasonal variation in cereal consumption in Southern region households covered by the IHS3 (data not shown).

Conversely, other crops showed marked seasonal variation. For example, mean consumption per AME of 'Legumes' was $>87 \mathrm{~g} \mathrm{~d}^{-1} \mathrm{DW}$ in May-July but $<55 \mathrm{~g} \mathrm{~d}^{-1}$ DW in October-March. Consumption of 'Roots and tubers' peaked during May-September, 'Vegetables' during March and April and 'Fruit' during January and February coinciding with the availability of mangoes; there were 3226 records of mango consumption of which 79 \% were in November-January. Fish is a particularly important component of dietary micronutrient supply and there was no marked seasonal variation in consumption nationally (Fig. 2; Additional file 1: Table S15). Of relevance to food fortification schemes, 11,950 (99\%), 7756 (64\%) and 7611 (63\%) of households reported consuming salt, sugar and cooking oil, respectively.

\section{Nutrient supplies and prevalence of inadequate intakes at household levels \\ Energy}

Nationally, median energy supplies per capita and per AME were 2114 and $2463 \mathrm{kcal} \mathrm{d}^{-1}$, respectively, but were lower in rural areas (Tables 1 and 2; Additional file 1: Table S16 and Additional file 1: Table S17). For 


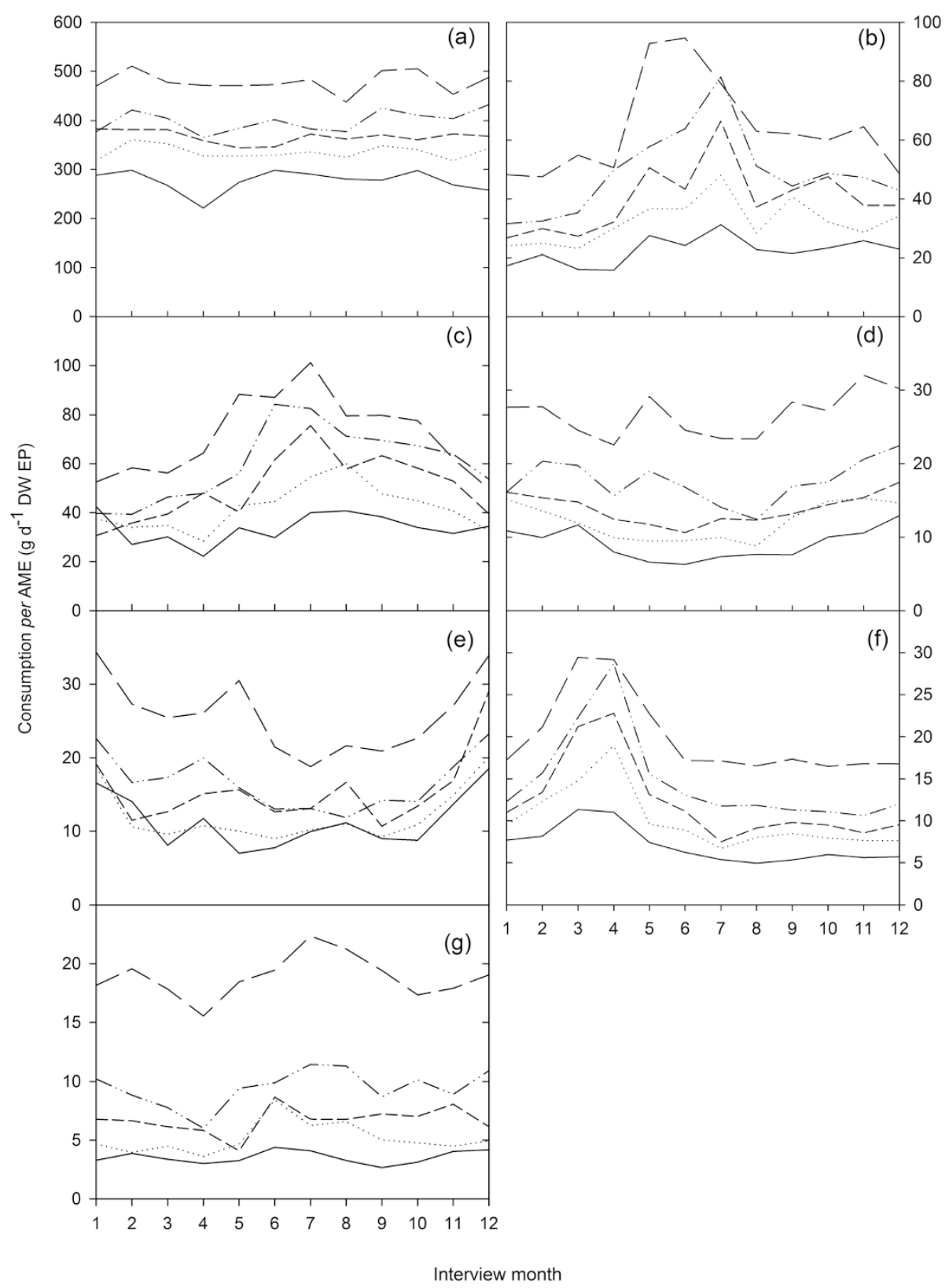

Fig. 2 Seasonal supply of food groups. Median daily supply of the food groups a cereals, $\mathbf{b}$ legumes, $\mathbf{c}$ roots and tubers, $\mathbf{d}$ fish, e fruits, $\mathbf{f}$ vegetables and $\mathbf{g}$ animal products (not including fish) per Adult Male Equivalent, dry-weight edible portion (AME, DW EP) by expenditure quintile and interview month (1 - January to 12 - December). Quintiles are 1 (poorest, continuous), 2 (dot), 3 (short-dash), 4 (dash-dot-dot) and 5 (wealthiest, long-dash)

comparison, the DER of an adult man with body mass $70 \mathrm{~kg}$ and physical activity level 1.9 is $3300 \mathrm{kcal} \mathrm{d}^{-1}$ [38]. Median household supply of energy as a proportion of sum of member DERs was 0.92 (Additional file 1: Table S18 and Additional file 1: Table S19). Overall, $57 \%$ of households reported consumption of insufficient calories to meet the sum of member DERs (Additional file 1: Table S20 and Additional file 1: Table S21). Among EPAs, median energy supply per AME ranged from $1127 \mathrm{kcal} \mathrm{d}^{-1}$ in Kalumba (number of households, $n=$
16) to $3817 \mathrm{kcal} \mathrm{d}^{-1}$ in Nkhunga $(n=125)$ and was $<2000 \mathrm{kcal} \mathrm{d}^{-1}$ or $>4000 \mathrm{kcal} \mathrm{d}^{-1}$ in 33 of 179 EPAs (Additional file 1: Table S22 and Additional file 1: Table S23). Thus, despite data cleaning as described in the Methods and use of median household nutrient supplies during aggregation, there remains an issue with implausible dietary energy (and other nutrient) supplies. This is re-visited in the Discussion.

Household dietary energy supply was related to household socioeconomic characteristics (Fig. 3). For example, 
Table 1 Nutrient supplies in rural households

\begin{tabular}{|c|c|c|c|c|c|c|c|c|c|c|c|}
\hline \multirow[t]{3}{*}{ Expenditure quintile } & \multirow[t]{3}{*}{$n$} & \multicolumn{10}{|c|}{ Median dietary supply } \\
\hline & & Energy & $\mathrm{Ca}$ & $\mathrm{Cu}$ & $\mathrm{Fe}$ & I & $\mathrm{Mg}$ & $\mathrm{Se}$ & $\mathrm{Zn}$ & PA & $P A: Z n$ \\
\hline & & kcal & & $\mathrm{mg}$ & & $\mu \mathrm{g}$ & $\mathrm{mg}$ & $\mu \mathrm{g}$ & \multicolumn{2}{|c|}{$\mathrm{mg}$} & Molar ratic \\
\hline & & \multicolumn{10}{|c|}{$\mathrm{AME}^{-1} \mathrm{~d}^{-1}$} \\
\hline 1 & 1783 & 1479 & 307 & 0.98 & 11.5 & 5.5 & 303 & 12.6 & 6.1 & 1976 & 35.2 \\
\hline 2 & 2038 & 1976 & 510 & 1.40 & 16.0 & 9.3 & 397 & 18.6 & 7.9 & 2401 & 32.3 \\
\hline 3 & 2103 & 2423 & 636 & 1.78 & 19.5 & 12.1 & 464 & 22.5 & 9.3 & 2680 & 30.7 \\
\hline 4 & 2140 & 2870 & 830 & 2.23 & 23.6 & 16.8 & 548 & 28.8 & 11.5 & 2951 & 28.2 \\
\hline 5 & 1880 & 3828 & 1304 & 3.28 & 30.8 & 26.9 & 741 & 43.3 & 16.1 & 3846 & 24.8 \\
\hline ALL & 9944 & 2384 & 649 & 1.80 & 19.5 & 12.6 & 469 & 23.5 & 9.6 & 2764 & 30.2 \\
\hline
\end{tabular}

Median energy, calcium (Ca), copper (Cu), iron (Fe), iodine (I), magnesium (Mg), selenium (Se), zinc (Zn) and phytic acid (PA) supplies per Adult Male Equivalent (AME) in rural households by household expenditure quintile ( 1 = poorest, $5=$ highest). ' $n$ ' is the number of households. lodine supply excludes salt

$92 \%$ of households in quintile 1 had inadequate energy supply to meet sum of member DERs compared to $28 \%$ in quintile 5 (Additional file 1: Table S20).

The food groups 'Cereals', 'Legumes' and 'Roots and tubers' contributed 61, 10 and $9 \%$, respectively, of mean national dietary energy supply; other food groups contributed $<6 \%$ each (Additional file 1: Table S24, Additional file 1: Table S25 and Additional file 1: Table S26).

\section{Calcium}

Nationally, median Ca supplies per capita and per AME were 602 and $704 \mathrm{mg} \mathrm{d}^{-1}$, respectively, but were lower in rural areas (Tables 1 and 2; Additional file 1: Table S16 and Additional file 1: Table S17). For comparison, the RNI for an adult man is $750 \mathrm{mg} \mathrm{d}^{-1}$ [39]. Median household supplies of $\mathrm{Ca}$ as a proportion of sum of member EARs and RNIs were 1.0 and 0.9, respectively (Additional file 1: Table S18 and Additional file 1: Table S19). Overall, 49 and $57 \%$ of households did not consume enough $\mathrm{Ca}$ to meet the sum of member EARs and RNIs, respectively (Table 3; Additional file 1: Table S20 and Additional file 1: Table S21). Among EPAs, median Ca supply per AME ranged from $210 \mathrm{mg} \mathrm{d}^{-1}$ in Kavukuku
( $n=64)$ to $1896 \mathrm{mg} \mathrm{d}^{-1}$ in Chiweta $(n=16$; Additional file 1: Table S22 and Additional file 1: Table S23).

Household dietary Ca supply varied due to household socioeconomic characteristics, soil type and proximity to Lake Malawi (Figs. 3 and 4). For example, $83 \%$ of households in quintile 1 had inadequate $\mathrm{Ca}$ supply to meet sum of member EARs compared to $22 \%$ in quintile 5 (Additional file 1: Table S20). Nationally, median Ca supply as a proportion of energy supply was $291 \mathrm{mg}$ $1000 \mathrm{kcal}^{-1}$ and was 222 and $360 \mathrm{mg} 1000 \mathrm{kcal}^{-1}$ in quintiles 1 and 5, respectively, and 368 and $274 \mathrm{mg}$ $1000 \mathrm{kcal}^{-1}$ in urban and rural households, respectively (Additional file 1: Table S27).

The food groups 'Fish' and 'Vegetables' contributed 62 and $15 \%$, respectively, of national annual dietary $\mathrm{Ca}$ supply and adequacy of Ca supply was related to consumption of fish; other food groups contributed $<7 \%$ each (Additional file 1: Table S24, Additional file 1: Table S25 and Additional file 1: Table S26). Dairy products are an important source of dietary $\mathrm{Ca}$ in many countries, e.g. $36 \%$ of dietary Ca intake in the UK [46], but in the present study they contributed $<2 \%$ of national $\mathrm{Ca}$ supply. Median household supplies of $\mathrm{Ca}$ as a proportion of sum of member EARs were 1.32 and

Table 2 Nutrient supplies in urban households

\begin{tabular}{|c|c|c|c|c|c|c|c|c|c|c|c|}
\hline \multirow[t]{3}{*}{ Expenditure quintile } & \multirow[t]{3}{*}{$n$} & \multicolumn{10}{|c|}{ Median dietary supply } \\
\hline & & Energy & $\mathrm{Ca}$ & $\mathrm{Cu}$ & $\mathrm{Fe}$ & 1 & $\mathrm{Mg}$ & $\mathrm{Se}$ & $\mathrm{Zn}$ & $\mathrm{PA}$ & $P A: Z n$ \\
\hline & & kcal & & $\mathrm{mg}$ & & $\mu \mathrm{g}$ & $\mathrm{mg}$ & $\mu \mathrm{g}$ & \multicolumn{2}{|c|}{$\mathrm{mg}$} & Molar ratio \\
\hline & & \multicolumn{10}{|c|}{$A M E^{-1} d^{-1}$} \\
\hline 1 & 57 & 1343 & 425 & 1.09 & 10.4 & 7.0 & 291 & 15.7 & 6.1 & 1951 & 32.2 \\
\hline 2 & 135 & 1784 & 645 & 1.49 & 12.1 & 11.5 & 327 & 19.7 & 7.7 & 1772 & 29.0 \\
\hline 3 & 228 & 2123 & 751 & 1.60 & 14.4 & 14.2 & 344 & 21.3 & 8.2 & 1814 & 25.4 \\
\hline 4 & 442 & 2404 & 860 & 1.91 & 16.1 & 18.1 & 390 & 26.1 & 9.6 & 2049 & 23.5 \\
\hline 5 & 1311 & 3325 & 1257 & 2.95 & 21.5 & 31.3 & 540 & 39.4 & 13.9 & 2416 & 18.4 \\
\hline ALL & 2173 & 2830 & 1021 & 2.30 & 18.2 & 24.1 & 465 & 32.2 & 11.5 & 2261 & 20.4 \\
\hline
\end{tabular}

Median energy, calcium (Ca), copper (Cu), iron (Fe), iodine (I), magnesium (Mg), selenium (Se), zinc (Zn) and phytic acid (PA) supplies per Adult Male Equivalent (AME) in urban households by household expenditure quintile $(1=$ poorest, $5=$ highest). ' $n$ ' is the number of households. lodine supply excludes salt 


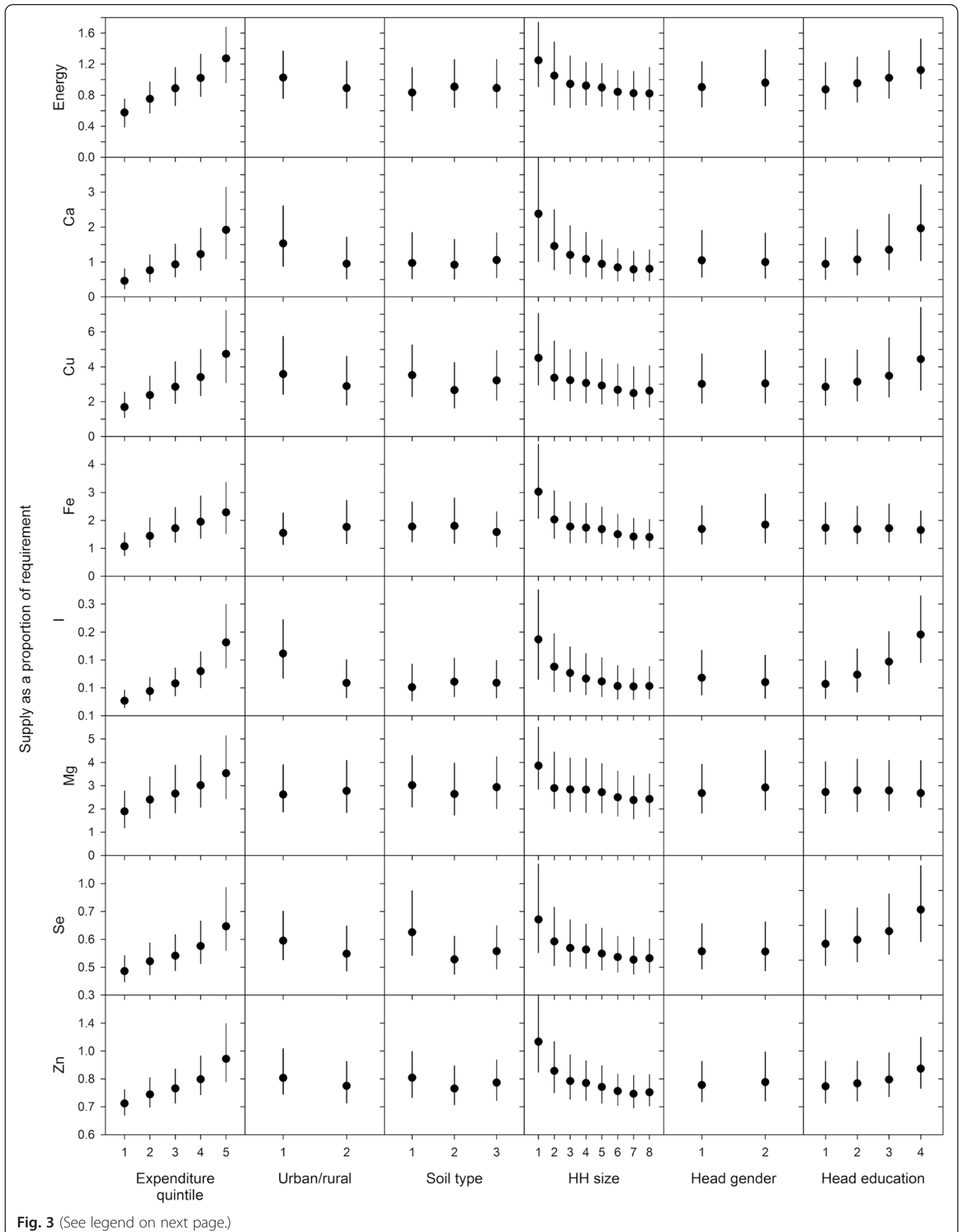


(See figure on previous page.)

Fig. 3 Adequacy of household nutrient supplies by household characteristics. Household energy, calcium (Ca), copper (Cu), iron (Fe), iodine (I), magnesium (Mg), selenium ( $\mathrm{Se}$ ) and zinc (Zn) supplies divided by sum of member requirements. Supply of I excludes salt. Households are grouped by expenditure quintile ( 1 = poorest to $5=$ wealthiest), urban/rural location, soil type $(1=$ calcareous, $2=$ non-calcareous, $3=$ undifferentiated $)$, household size (capped at 8 ), head gender ( 1 = male, 2 = female) and head education ( 1 = none, 2 = primary school leaving certificate, $3=$ junior certificate of education, 4 = Malawi school certificate of education). Points represent median values, bars represent first and third quartiles, respectively

0.37 in households that did and did not consume fish, respectively. Dietary supplies of Ca were greater in lakeshore EPAs (Fig. 4) due to greater consumption of fish.

\section{Copper}

Nationally, median $\mathrm{Cu}$ supplies per capita and per AME were 1.62 and $1.88 \mathrm{mg} \mathrm{d}^{-1}$, respectively, but were lower in rural areas (Tables 1 and 2; Additional file 1: Table S16 and Additional file 1: Table S17). For comparison, the RNI for an adult man is $0.9 \mathrm{mg} \mathrm{d}^{-1}$ [40]. Median household supplies of $\mathrm{Cu}$ as a proportion of sum of member EARs and RNIs were 3.0 and 2.5, respectively (Additional file 1: Table S18 and Additional file 1: Table S19). Overall, 6 and $9 \%$ of households were not consuming enough $\mathrm{Cu}$ to meet the sum of member EARs and RNIs, respectively (Additional file 1: Table S20 and Additional file 1: Table S21). Among EPAs, median $\mathrm{Cu}$ supply per AME ranged from $0.72 \mathrm{mg} \mathrm{d}^{-1}$ in Kalumba $(n=16)$ to $4.68 \mathrm{mg} \mathrm{d}^{-1}$ in Mbulumbuzi $(n=47$; Additional file 1: Table S22 and Additional file 1: Table S23).

Household dietary $\mathrm{Cu}$ supply was related to household socioeconomic characteristics (Fig. 3). For example, $22 \%$ of households in quintile 1 had inadequate $\mathrm{Cu}$ supply to meet sum of member EARs compared to $<1 \%$ in quintile 5 (Additional file 1: Table S20). Nationally, median Cu supply as a proportion of energy was $0.79 \mathrm{mg} 1000 \mathrm{kcal}^{-1}$ and was 0.74 and $0.87 \mathrm{mg} 1000 \mathrm{kcal}^{-1}$ in quintiles 1 and 5, respectively (Additional file 1: Table S27).

The food groups 'Cereals', 'Legumes' and 'Fish' contributed 24, 23 and $22 \%$, respectively, of national annual dietary $\mathrm{Cu}$ supply; other food groups contributed $<11 \%$ each (Additional file 1: Table S24, Additional file 1: Table S25 and Additional file 1: Table S26).

\section{Iron}

Nationally, median Fe supplies per capita and per AME were 16.6 and $19.2 \mathrm{mg} \mathrm{d}^{-1}$, respectively, and were greater in rural areas (Tables 1 and 2; Additional file 1: Table S16 and Additional file 1: Table S17). For comparison, the RNI for an adult man is $13.7 \mathrm{mg} \mathrm{d}^{-1}$ but $49.4 \mathrm{mg} \mathrm{d}^{-1}$ for a pregnant woman [39]. Median household supplies of Fe as a proportion of sum of member EARs and RNIs were 1.72 and 1.43, respectively (Additional file 1: Table S18 and Additional file 1: Table S19). Overall, 18 and $27 \%$ of households were not consuming enough $\mathrm{Fe}$ to meet the sum of member EARs and RNIs, respectively (Additional file 1: Table S20 and Additional file 1: Table S21). Among
EPAs, median Fe supply per AME ranged from $7.9 \mathrm{mg} \mathrm{d}^{-1}$ in Kalumba $(n=16)$ to $34.1 \mathrm{mg} \mathrm{d}^{-1}$ in Mbulumbuzi $(n=47$; Additional file 1: Table S22 and Additional file 1: Table S23). Nationally, $8 \%$ of households had Fe supplies per AME $>45 \mathrm{mg} \mathrm{d}^{-1}$, the tolerable upper level of intake for adults [39].

Household dietary Fe supply was related to socioeconomic characteristics (Fig. 3). For example, $45 \%$ of households in quintile 1 had inadequate Fe supply to meet sum of member EARs compared to $7 \%$ in quintile 5 (Additional file 1: Table S20). Adequacy of household Fe supply varied seasonally according to Fe supply from vegetables, consumption of which peak in FebruaryApril (Fig. 2). Nationally, median Fe supply as a proportion of energy was $7.5 \mathrm{mg} 1000 \mathrm{kcal}^{-1}$ and showed little variation between expenditure quintiles, but was greater in rural than urban households, i.e. 7.9 versus $6.4 \mathrm{mg}$ $1000 \mathrm{kcal}^{-1}$ (Additional file 1: Table S27).

The food groups 'Cereals', 'Vegetables', 'Legumes' and 'Fish' contributed 34, 29, 12 and $11 \%$, respectively, of national annual dietary Fe supply. Other food groups contributed $<5 \%$ each (Additional file 1: Table S24, Additional file 1: Table S25 and Additional file 1: Table S26).

\section{lodine}

The majority of dietary I supply for most households is likely to come from salt due to mandatory iodisation at $>15 \mathrm{mg} \mathrm{kg}^{-1}$ in Malawi. Data for household salt consumption were captured in the IHS3 but the concentration of I in salt is highly variable depending on level of iodisation at manufacture and losses due to improper storage [47]. Not including salt, median supplies per capita and per AME were 12.2 and $14.3 \mu \mathrm{g} \mathrm{d}^{-1}$, respectively, but were lower in rural areas (Tables 1 and 2; Additional file 1: Table S16 and Additional file 1: Table S17). For comparison, the RNI for an adult man is $150 \mu \mathrm{g} \mathrm{d}^{-1}$ [39]. Median household supplies of I as a proportion of sum of member EARs and RNIs were 0.13 and 0.11, respectively (Additional file 1: Table S18 and Additional file 1: Table S19). Overall, 99 and $100 \%$ of households were not consuming enough I through food items other than salt to meet the sum of member EARs and RNIs, respectively (Additional file 1: Table S20 and Additional file 1: Table S21). Among EPAs, median I supply per AME ranged from $5.1 \mu \mathrm{g} \mathrm{d}^{-1}$ in Dolo $(n=63)$ to $28.1 \mu \mathrm{g} \mathrm{d}^{-1}$ in Ntonda $(n=431$; Additional file 1 : Table S22 and Additional file 1: Table S23). 
Table 3 National prevalence of inadequate dietary calcium (Ca), iron (Fe), selenium (Se) or zinc (Zn) supplies at household level Urban/rural Expenditure quintile Soil type $n \quad \mathrm{Ca} \quad \mathrm{Fe} \quad \mathrm{Se} \quad \mathrm{Zn}$ \begin{tabular}{llllllll} 
& & \multicolumn{5}{c}{$\%$} \\
\hline ALL & ALL & ALL & 12117 & 49 & 18 & 74 & 57
\end{tabular}

ALL

Urban

Rural ALL

\begin{tabular}{|c|c|c|c|c|c|}
\hline ALL & ALL & 9944 & 52 & 18 & 75 \\
\hline 1 & & 1783 & 83 & 45 & 92 \\
\hline 2 & & 2038 & 66 & 22 & 86 \\
\hline 3 & & 2103 & 55 & 12 & 81 \\
\hline 4 & & 2140 & 39 & 8 & 70 \\
\hline 5 & & 1880 & 22 & 4 & 49 \\
\hline ALL & 1 & 2047 & 51 & 16 & 55 \\
\hline & 2 & 6523 & 54 & 18 & 82 \\
\hline & 3 & 1374 & 48 & 21 & 75 \\
\hline 1 & 1 & 493 & 82 & 37 & 79 \\
\hline 2 & & 450 & 62 & 16 & 67 \\
\hline 3 & & 385 & 51 & 8 & 55 \\
\hline 4 & & 379 & 28 & 5 & 37 \\
\hline 5 & & 340 & 18 & 4 & 25 \\
\hline 1 & 2 & 1000 & 85 & 48 & 97 \\
\hline 2 & & 1297 & 69 & 22 & 93 \\
\hline 3 & & 1424 & 58 & 13 & 88 \\
\hline 4 & & 1467 & 43 & 9 & 80 \\
\hline 5 & & 1335 & 23 & 4 & 55 \\
\hline 1 & 3 & 290 & 80 & 48 & 93 \\
\hline 2 & & 291 & 61 & 27 & 85 \\
\hline 3 & & 294 & 40 & 14 & 78 \\
\hline 4 & & 294 & 31 & 8 & 67 \\
\hline 5 & & 205 & 18 & 4 & 43 \\
\hline
\end{tabular}

Percentage of households with dietary supply less than sum of household member Estimated Average Requirements, by urban/rural location, expenditure quintile $(1=$ poorest, $5=$ highest $)$ and soil type $(1=$ calcareous; $2=$ non-calcareous; 3 = undifferentiated)

Nationally, median consumption of salt per AME was $11.2 \mathrm{~g} \mathrm{~d}^{-1}$, was greater in rural than urban households (median 11.4 versus $10.3 \mathrm{~g} \mathrm{~d}^{-1}$ ) and was related to expenditure quintile, with median consumption of 8.5 ,
$10.0,10.9,12.4$ and $15.4 \mathrm{~g} \mathrm{~d}^{-1}$ for quintiles 1 to 5 , respectively. If it is assumed that all salt was iodised at $15 \mathrm{mg} \mathrm{kg} \mathrm{kg}^{-1}$ and consumed, then 17 and $27 \%$ of households would not be consuming enough I to meet the sum of member EARs and RNIs, respectively. Further salt consumption and iodisation scenarios are explored in the Discussion section. Median I supply from foods other than salt as a proportion of energy was $5.80 \mu \mathrm{g}$ $1000 \mathrm{kcal}^{-1}$ and was 3.7 and $8.1 \mu \mathrm{g} 1000 \mathrm{kcal}^{-1}$ in quintiles 1 and 5, respectively (Additional file 1: Table S27). The food group 'Fish' supplied $49 \%$ of I from non-salt food sources (Additional file 1: Table S26).

\section{Magnesium}

Nationally, median Mg supplies per capita and per AME were 401 and $468 \mathrm{mg} \mathrm{d}^{-1}$, respectively, and were similar in rural and urban areas (Tables 1 and 2; Additional file 1: Table S16 and Additional file 1: Table S17). For comparison, the RNI for an adult man is $260 \mathrm{mg} \mathrm{d}^{-1}$ [39]. Median household supplies of $\mathrm{Mg}$ as a proportion of sum of member EARs and RNIs were 2.74 and 2.28, respectively (Additional file 1: Table S18 and Additional file 1: Table S19). Overall, 5 and $9 \%$ of households were not consuming enough $\mathrm{Mg}$ to meet the sum of member EARs and RNIs, respectively (Additional file 1: Table S20 and Additional file 1: Table S21). Among EPAs, median $\mathrm{Mg}$ supply per AME ranged from $182 \mathrm{mg} \mathrm{d}^{-1}$ in Kalumba $(n=16)$ to $827 \mathrm{mg} \mathrm{d}^{-1}$ in Masambanjati ( $n=32$; Additional file 1: Table S22 and Additional file 1: Table S23).

Household dietary Mg supply was related to household socioeconomic characteristics (Fig. 3). For example, $17 \%$ of households in quintile 1 had inadequate $\mathrm{Mg}$ supply to meet sum of member EARs compared to $1 \%$ in quintile 5 (Additional file 1: Table S20). Nationally, median $\mathrm{Mg}$ supply as a proportion of energy was $207 \mathrm{mg} 1000 \mathrm{kcal}^{-1}$ and was 242 and $186 \mathrm{mg} 1000 \mathrm{kcal}^{-1}$ in quintiles 1 and 5, respectively (Additional file 1: Table S27).

The food groups 'Cereals', 'Legumes' and 'Vegetables' contributed 45, 19 and $11 \%$, respectively, of national annual dietary Mg supply; other food groups contributed $<10 \%$ each (Additional file 1: Table S24, Additional file 1: Table S25 and Additional file 1: Table S26).

\section{Selenium}

Nationally, median Se supplies per capita and per AME were 21.4 and $25.0 \mu \mathrm{g} \mathrm{d}^{-1}$, respectively, but were lower in rural areas (Tables 1 and 2; Additional file 1: Table S16 and Additional file 1: Table S17). For comparison, the RNI for an adult man is $55 \mu \mathrm{g} \mathrm{d}^{-1}$ [41]. Median household supplies of $\mathrm{Se}$ as a proportion of sum of member EARs and RNIs were 0.63 and 0.52 , respectively (Additional file 1: Table S18 and Additional file 1: Table S19). Overall, 74 and $81 \%$ of households were not 


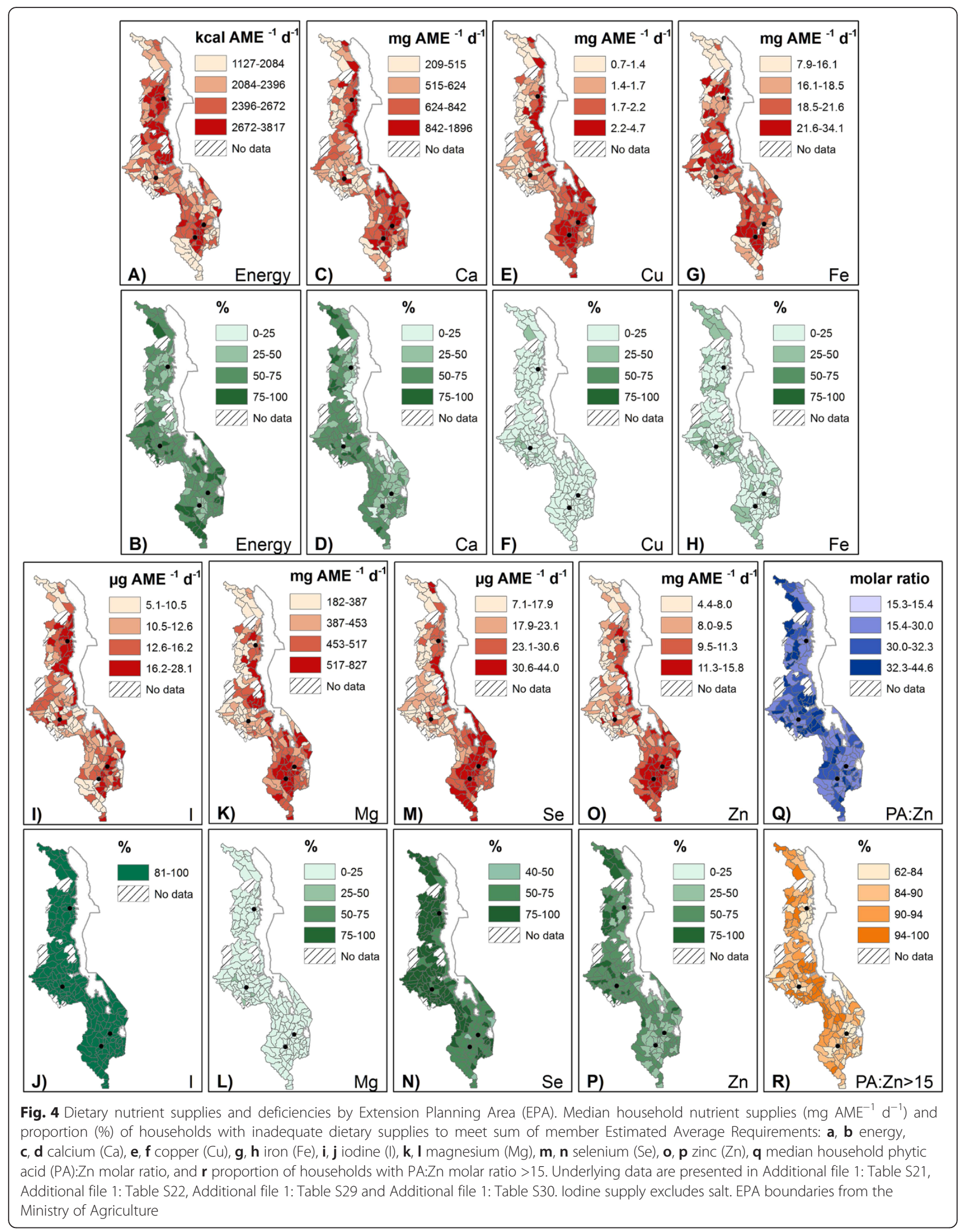


consuming enough Se to meet the sum of member EARs and RNIs, respectively (Fig. 5; Additional file 1: Table S20 and Additional file 1: Table S21). Among EPAs, median Se supply per AME ranged from $7.1 \mu \mathrm{g} \mathrm{d}^{-1}$ in Kavukuku $(n=$ 64) to $43.9 \mu \mathrm{g} \mathrm{d}^{-1}$ in Nampeya $(n=47$; Additional file 1 : Table S22 and Additional file 1: Table S23).

Household dietary Se supply varied due to household socioeconomic characteristics and soil type (Figs. 3, 4 and 5). For example, 55 and $82 \%$ of households on calcareous and non-calcareous soils, respectively, had inadequate Se supply to meet sum of member EARs and there was a 92 and $51 \%$ prevalence of inadequate supplies among households from expenditure quintiles 1 and 5, respectively (Additional file 1: Table S20). Nationally, median Se supply as a proportion of energy was $10.2 \mu \mathrm{g} 1000 \mathrm{kcal}^{-1}$ and was 9.0 and $11.7 \mu \mathrm{g} 1000 \mathrm{kcal}^{-1}$ in quintiles 1 and 5, respectively, and 15.6 and $8.4 \mu \mathrm{g}$ $1000 \mathrm{kcal}^{-1}$ in rural households on calcareous and noncalcareous soils, respectively (Additional file 1: Table S27).

The food groups 'Fish', 'Cereals' and 'Legumes' contributed 47,21 and $13 \%$, respectively, of national annual dietary Se supply; other food groups contributed $<9 \%$ each (Additional file 1: Table S24, Additional file 1: Table S25 and Additional file 1: Table S26). 'Cereals' contributed 28 and $19 \%$ of dietary Se supply among rural households on calcareous and non-calcareous soils, respectively (Additional file 1: Table S26).

\section{Zinc}

Nationally, median Zn supplies per capita and per AME were 8.5 and $10.0 \mathrm{mg} \mathrm{d}^{-1}$, respectively, but were lower in rural areas (Tables 1 and 2; Additional file 1: Table S16 and Additional file 1: Table S17). For comparison, the RNI for an adult man is $14 \mathrm{mg} \mathrm{d}^{-1}$ [39]. Median household supplies of $\mathrm{Zn}$ as a proportion of sum of member EARs and RNIs were 0.90 and 0.75 , respectively (Additional file 1: Table S18 and Additional file 1: Table S19). Overall, 57 and $68 \%$ of households were not consuming enough $\mathrm{Zn}$ to meet the sum of member EARs and RNIs, respectively (Additional file 1: Table S20 and Additional file 1: Table S21). Among EPAs, median $\mathrm{Zn}$ supply per AME ranged from $4.4 \mathrm{mg} \mathrm{d}^{-1}$ in

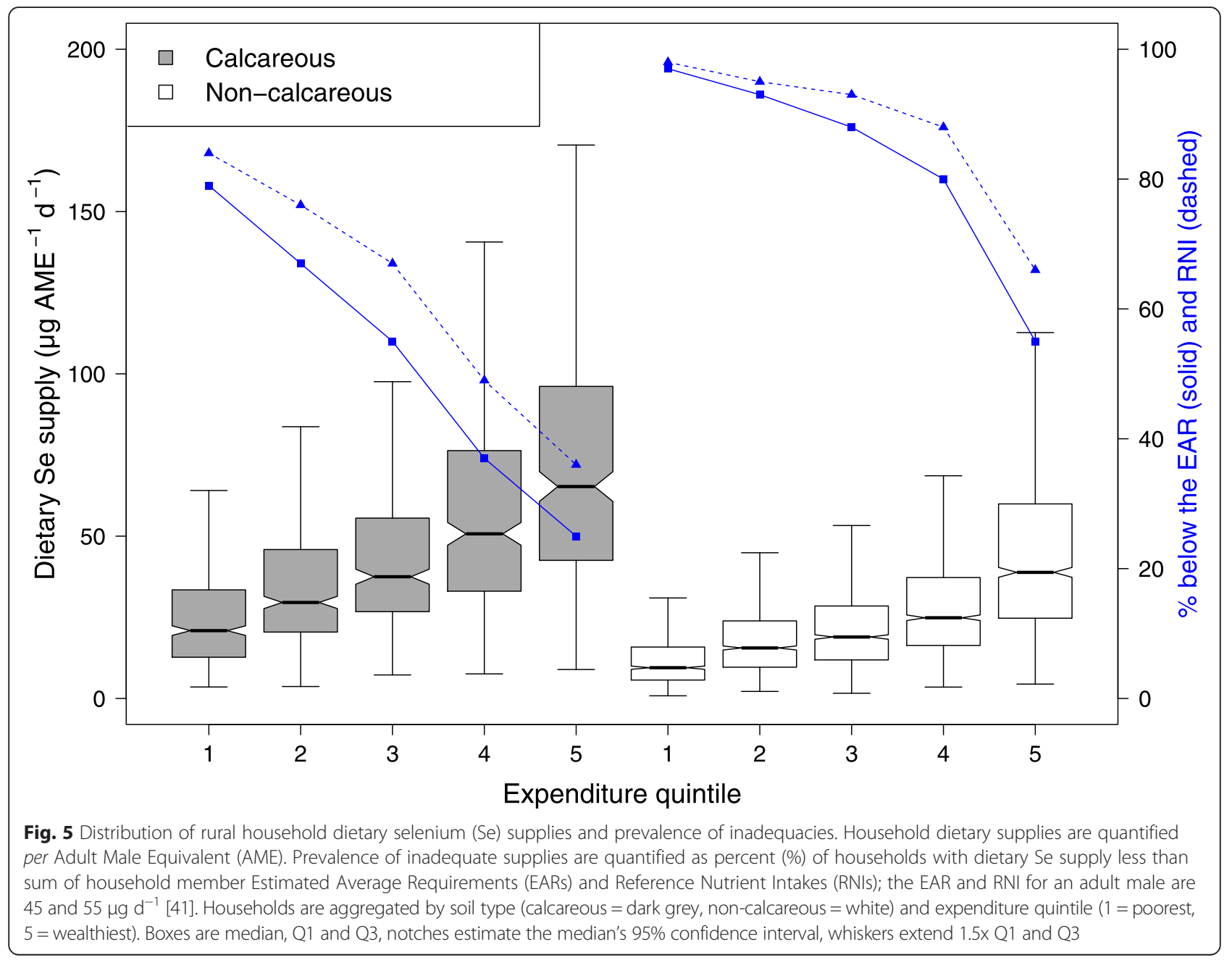


Kalumba $(n=16)$ to $15.8 \mathrm{mg} \mathrm{d}^{-1}$ in Masambanjati $(n=$ 32; Additional file 1: Table S22 and Additional file 1: Table S23).

Household dietary Zn supply varied spatially and was related to household socioeconomic characteristics (Figs. 3 and 4). For example, $88 \%$ of households in quintile 1 had inadequate $\mathrm{Zn}$ supply to meet sum of member EARs compared to $28 \%$ in quintile 5 (Additional file 1: Table S20). Nationally, median Zn supply as a proportion of energy was $4.2 \mathrm{mg} 1000 \mathrm{kcal}^{-1}$ and was 5.4 and $4.0 \mathrm{mg} 1000 \mathrm{kcal}^{-1}$ for households on calcareous and non-calcareous soils, respectively (Additional file 1: Table S27).

The food groups 'Cereals', 'Fish' and 'Legumes' contributed 41, 26 and $13 \%$, respectively, of national annual dietary Zn supply; other food groups contributed $<7 \%$ each (Additional file 1: Table S24, Additional file 1: Table S25 and Additional file 1: Table S26). Dietary supplies of $\mathrm{Zn}$ were greater in lakeshore EPAs due to greater consumption of fish (Fig. 4).

\section{Phytic acid}

Nationally, median dietary PA supplies per capita and per AME were 2280 and $2460 \mathrm{mg} \mathrm{d}^{-1}$, respectively and median dietary PA:Zn molar ratio was 29 (Additional file 1: Table S16, Additional file 1: Table S17 and Additional file 1: Table S18). Overall, $87 \%$ of households had dietary PA:Zn molar ratios $>15.0$ (Additional file 1: Table S20). Household dietary PA:Zn molar ratio was related to household socioeconomic characteristics. For example, median PA:Zn molar ratios were 20 and 30 in urban and rural households, respectively, and 35 and 22 in expenditure quintiles 1 and 5, respectively (Tables 1 and 2; Additional file 1: Table S18). Among EPAs, median PA supply per AME ranged from $981 \mathrm{mg} \mathrm{d}^{-1}$ in Nthondo $(n=16)$ to $4580 \mathrm{mg} \mathrm{d}^{-1}$ in Masambanjati $(n=32)$ while the median PA:Zn molar ratio ranged from 15 in Chiweta $(n=16)$ to 45 in Nakachoka $(n=32$; Additional file 1: Table S22 and Additional file 1: Table S23).

The food groups 'Cereals' and 'Legumes' contributed 65 and $28 \%$, respectively, of dietary PA supply (Additional file 1: Table S26) and PA:Zn molar ratio was greatest (therefore lowest bioavailability of $\mathrm{Zn}$ ) during the harvest season of May-August (Fig. 6), mainly due to greater consumption of legumes.

\section{Discussion}

\section{Comparison with previous estimates of dietary nutrient supplies}

The present study estimated dietary mineral element supplies at household levels in Malawi by combining food supply data captured in the IHS3 [28] with locallygenerated food crop composition data [18, 48]. This compares with previous efforts to quantify the prevalence of inadequate element intakes at wide scales in Malawi on the basis of national-level food supply data captured in Food Balance Sheets (FBSs) published by the FAO matched with published or local composition data $[5,9,10,13,18,22,27,49,50]$ or food consumption from household surveys matched with published composition data $[29,30]$.

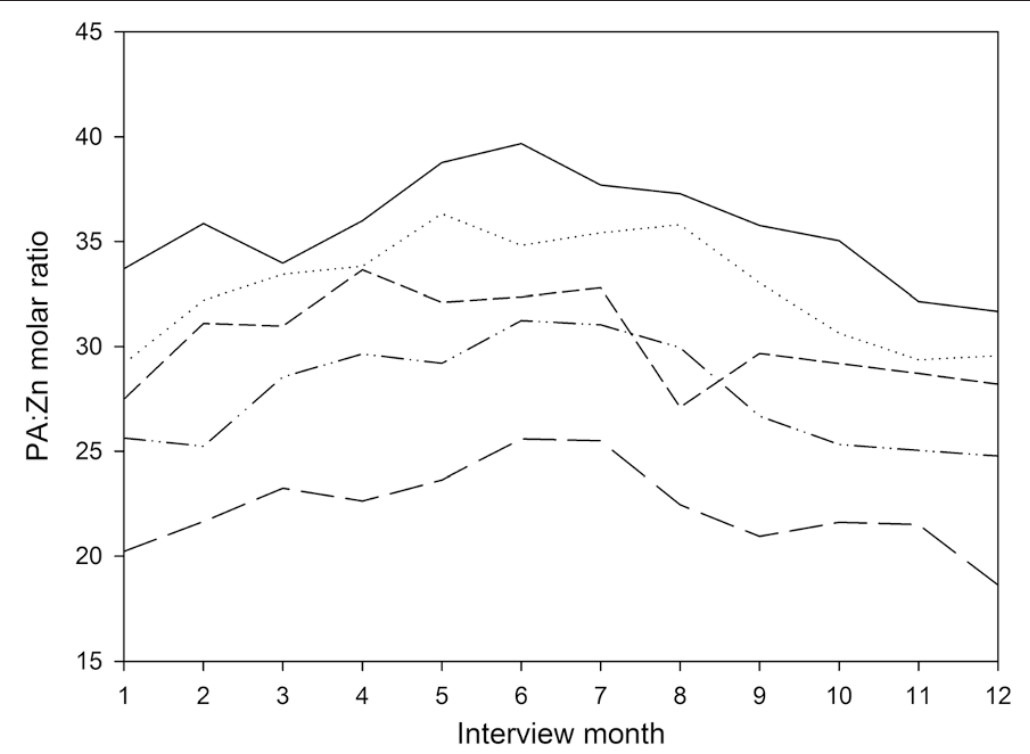

Fig. 6 Seasonal phytic acid:zinc (PA:Zn) molar ratio in the diet. Median household dietary PA:Zn molar ratio by interview month. A diet with PA:Zn molar ratio $>15$ is likely to supply inadequate bioavailable Zn [17]. Quintiles are 1 (poorest, continuous), 2 (dot), 3 (short-dash), 4 (dash-dot-dot) and 5 (wealthiest, long-dash) 
Where appropriate, the estimated prevalence of inadequate dietary element intakes are discussed in relation to the 2010 Global Burden of Disease study, coordinated by the Institute for Health Metrics and Evaluation (IHME), in which all-cause mortality and morbidity were assigned to 67 underlying risk factors [7, 51, 52]. The Global Burden of Disease study used Disability-Adjusted Life-Years (DALYs) as a common currency to measure disease burden. A DALY is equivalent to a lost year of 'healthy life' and is the sum of years of life lost due to premature mortality and years of life lost due to a disability [53].

\section{Energy}

Previously, Joy et al. [9] estimated mean national dietary supply of energy in Malawi to be $2757 \mathrm{kcal}_{\text {capita }}{ }^{-1} \mathrm{~d}^{-1}$ based on FBS data while Verduzco-Gallo et al. [30] reported mean consumption of $2305 \mathrm{kcal} \mathrm{capita}^{-1} \mathrm{~d}^{-1}$ based on the IHS3. This compares to estimated mean and median consumption of 2381 and $2115 \mathrm{kcal} \mathrm{capita}^{-1} \mathrm{~d}^{-1}$ in the present study. Verduzco-Gallo et al. [30] reported mean consumption of $1232 \mathrm{kcal}_{\text {capita }}{ }^{-1} \mathrm{~d}^{-1}$ and a $37 \%$ prevalence of inadequate energy intakes for rural households. This compares to mean and median consumption of 1258 and $1208 \mathrm{kcal}_{\text {capita }}{ }^{-1} \mathrm{~d}^{-1}$ and an estimated $60 \%$ prevalence of inadequate energy intakes for rural households in the present study. The greater estimated prevalence of inadequate energy intakes in the present study is due to different assumptions regarding energy requirements: Verduzco-Gallo et al. defined 'minimum calorie requirements' based on a light physical activity level (PAL) and low body mass index $[29,38]$. Thus, an adult male would be calorie deficient at intakes $<2400 \mathrm{kcal} \mathrm{d}^{-1}$ compared to $<3300 \mathrm{kcal} \mathrm{d}^{-1}$ in the present study where adults were assumed to lead a moderately active to active lifestyle with PAL of 1.9, consistent with expected activity given that $85 \%$ of the population are involved in agriculture, predominantly non-mechanised [31, 38]. Inadequate energy intakes are likely to be widespread among rural households, particularly during months of field preparation and weeding when PALs of 2.25 are estimated with requirements of $3850 \mathrm{kcal} \mathrm{d}^{-1}$ for men aged 18-30 [38].

Household spending data in the IHS3 support the finding of prevalent dietary energy insufficiency in poor households. Pauw et al. [54] reported that, as the wealth of poorest rural households increased, the share of income spent on food also increased. This appears contrary to Engel's law which states that the share of household budget spent on food is inversely related to household real income [55], a remarkably consistent observation across space and time [56]. The apparent contradiction could be explained if the poorest households are calorie insufficient and additional income is used to purchase essential food.

\section{Calcium}

Previously, Broadley et al. [13], Joy et al. [9] and Kumssa et al. [10] estimated mean national dietary supplies of $\mathrm{Ca}$ to be 306, 592 and $259 \mathrm{mg}$ capita $^{-1} \mathrm{~d}^{-1}$ based on FBS supply and published composition data. Subsequently, Joy et al. [18] estimated mean national dietary supplies of Ca to be 430 and $368 \mathrm{mg}$ capita ${ }^{-1} \mathrm{~d}^{-1}$ on calcareous and non-calcareous soils based on FBS supply and local composition data. In the present study, estimated national mean and median supplies of $\mathrm{Ca}$ were 924 and $602 \mathrm{mg}$ capita $^{-1} \mathrm{~d}^{-1}$, with median supplies of 578 and $537 \mathrm{mg} \mathrm{capita}^{-1} \mathrm{~d}^{-1}$ for rural households on calcareous and non-calcareous soils, respectively (Additional file 1: Table S16). The main reason for the greater estimated Ca supply in the present study is fish consumption. Mean national consumption of the food item 'Freshwater Fish' is reported in the 2009 FBS as $13 \mathrm{~g}$ capita $^{-1} \mathrm{~d}^{-1}$ on a fresh-weight (FW) basis [57] which is equivalent to $<3 \mathrm{~g}$ DW [18]. In contrast, estimated mean ( \pm standard deviation, SD) consumption of fish in the present study is $19 \pm 36$ g capita $^{-1} \mathrm{~d}^{-1}$ DW.

Despite the greater estimated consumption of fish, estimated prevalence of inadequate $\mathrm{Ca}$ intakes remains high with $49 \%$ of all households consuming less than sum of member EARs. This is due to the high inter-household variation in $\mathrm{Ca}$ supplies related to spatial and socio-economic factors, and low contribution of other food groups to dietary Ca supply, especially dairy products.

In the IHME Global Burden of Disease study [7], the annual disease burden in Malawi due to diets low in Ca was estimated to be 720 DALYs (100 k population $)^{-1}$ [51]. However, DALYs attributable to low dietary Ca were based only on the increased risk of prostate and colorectal cancers and not other diseases associated with inadequate dietary $\mathrm{Ca}$ such as rickets and osteoporosis [39], and the study is likely to underestimate the burden.

\section{Copper}

Previously, Joy et al. [9] estimated mean national dietary supply of $\mathrm{Cu}$ to be $3.0 \mathrm{mg}$ capita ${ }^{-1} \mathrm{~d}^{-1}$ based on FBS data and regional or international composition data, and subsequently, using local composition data, 2.6 and $2.0 \mathrm{mg}$ capita $^{-1} \mathrm{~d}^{-1}$ on calcareous and non-calcareous soils, respectively [18]. In the present study, estimated median dietary $\mathrm{Cu}$ supply was $1.6 \mathrm{mg}$ capita $^{-1} \mathrm{~d}^{-1}$ nationally, and 1.9 and $1.4 \mathrm{mg}$ capita $^{-1} \mathrm{~d}^{-1}$ for rural households on calcareous and non-calcareous soils, respectively (Additional file 1: Table S16). Removal of the husk and endosperm during milling of maize grain reduces the concentration of $\mathrm{Cu}$ by $\sim 80 \%$ (Additional file 1: Table S6). These losses were accounted for in the present study, resulting in lower estimated $\mathrm{Cu}$ supplies. 
Still, the estimated prevalence of inadequate $\mathrm{Cu}$ intakes is low which is consistent with previous findings [9].

\section{Iron}

Previously, Joy et al. [9] estimated mean national dietary supply of Fe to be $29.1 \mathrm{mg}$ capita $^{-1} \mathrm{~d}^{-1}$ based on FBS data and regional or international composition data, and subsequently, using local composition data, 23.2 and $18.4 \mathrm{mg}$ capita $^{-1} \mathrm{~d}^{-1}$ on calcareous and non-calcareous soils, respectively [18]. Verduzco-Gallo et al. [30] reported mean national dietary supplies of Fe to be $19.5 \mathrm{mg}$ capita ${ }^{-1} \mathrm{~d}^{-1}$ based on household survey data and regional or international composition data. In the present study, estimated national mean and median dietary Fe supplies were 20.4 and $16.6 \mathrm{mg}$ capita $^{-1} \mathrm{~d}^{-1}$.

The low estimated prevalence of inadequate Fe intakes is consistent with previous estimates based on FBS data $[9,18]$ and duplicate diet composites [23]. However, household consumption and requirement data aggregated at household level will underestimate the prevalence of Fe deficiency among adolescent and pregnant women because of their greater Fe requirements [39]. Verduzco-Gallo et al. [30] report similar median Fe supplies of $19.5 \mathrm{mg}$ capita $^{-1} \mathrm{~d}^{-1}$, but a $49 \%$ prevalence of inadequate intakes on the basis of food supply data from IHS3 and this might be due to different assumptions of Fe requirement or bioavailability. Nationally, the majority of dietary Fe supply came from non-haeme sources with only $14 \%$ from animal products including fish (Additional file 1: Table S26). Iron requirements were calculated assuming a low bioavilability (i.e. $10 \%$ ) [39]. However, a large proportion of Fe intake is likely to be attributable to inadvertent consumption of soil dust present on grains and leafy vegetables $[18,25]$, the bioavailability of which has not been adequately established.

Disease burden due to Fe deficiency was quantified for Malawi and other nations in the IHME Global Burden of Disease study on the basis of anaemia prevalence [7]. Thus, Fe deficiency was estimated to cause 1553 DALYs $(100 \mathrm{k} \text { population })^{-1}$ [51]. However, further research is required to determine whether $\mathrm{Fe}$ intakes are actually inadequate or whether other strategies to reduce Fe deficiency are required, for example focusing on diseases such as malaria or gut parasites that can reduce absorption and increase losses of Fe [58-60].

\section{lodine}

Estimated dietary supplies of I are limited in their relevance and accuracy without data on I intakes from salt. However, it is clear that supply of I from foods other than salt is inadequate to meet the requirements of almost $100 \%$ of households, with mean and median supplies of 17.7 and $12.2 \mu \mathrm{g}$ capita $^{-1} \mathrm{~d}^{-1}$ (Additional file 1: Table S16). The estimated proportion of households consuming adequately iodised salt in 2010 was $62 \%$ [61], suggesting that up to $38 \%$ of households are likely to be consuming inadequate $\mathrm{I}$ to meet requirements. Estimated supplies of I from foods other than salt is much lower than the previous estimate based on FBS data and regional or international composition data of $36.2 \mu \mathrm{g}$ capita $^{-1} \mathrm{~d}^{-1}$ from food sources other than salt [9] due to the use of locally generated food composition data in the present study. Scenarios of salt iodisation and consumption are explored in the section 'Interventions to improve dietary micronutrient supplies'.

The national I status of Malawi was recently defined as 'adequate' on the basis of urinary I concentrations (UIC) in school-aged children [62]. Also, the disease burden due to I deficiency has been quantified for Malawi and other nations in the IHME Global Burden of Disease study on the basis of goitre prevalence [52, 63]. Thus, a $28 \%$ prevalence of I deficiency in Malawi was estimated to cause 82 DALYs (100 k population) ${ }^{-1}$ [51]. However, this estimate is from a survey of goitre prevalence in school-aged children in seven districts of Malawi with endemic goitre conducted in 1996 [63, 64]; the study design bias and the use of goitre prevalence rather than UIC data is likely to over-estimate the burden of disease attributable to I deficiency, while the finding is likely to be out-dated considering that salt iodisation was only introduced as national policy in Malawi in 1995 [65, 66].

\section{Magnesium}

Previously, Broadley et al. [13], Kumssa et al. [50] and Joy et al. [9, 49] estimated mean national dietary supply of $\mathrm{Mg}$ to be $530-789 \mathrm{mg}$ capita $^{-1} \mathrm{~d}^{-1}$, based on FBS data and regional or international composition data, and subsequently, using local composition data, 712 and $632 \mathrm{mg}$ capita $^{-1} \mathrm{~d}^{-1}$ on calcareous and non-calcareous soils, respectively [18]. Estimated supplies of $\mathrm{Mg}$ are lower in the present study, with national mean and median of 479 and $401 \mathrm{mg}$ capita $^{-1} \mathrm{~d}^{-1}$. Removal of the husk and endosperm during milling of maize grain reduces the concentration of $\mathrm{Mg}$ by $\sim 80 \%$ (Additional file 1: Table S6). These losses were accounted for in the present study but not in previous studies which used whole grain composition data. Despite lower estimated $\mathrm{Mg}$ supplies, the estimated prevalence of inadequate $\mathrm{Mg}$ supplies remains low which is consistent with previous findings $[9,13,49]$, although deficiency may occur due to high dietary PA supplies [50].

\section{Selenium}

Previously, Joy et al. [9] estimated mean national dietary supply of Se to be $34 \mu$ g capita ${ }^{-1} \mathrm{~d}^{-1}$ based on FBS data and regional or international composition data, and subsequently, using local composition data, 41 and $19 \mu \mathrm{g}$ capita $^{-1} \mathrm{~d}^{-1}$ on calcareous and non-calcareous 
soils, respectively [18]. Similar estimates were found in the present study, with median Se supplies of 31 and $17 \mu \mathrm{g}$ capita $\mathrm{d}^{-1}$ for rural households on calcareous and non-calcareous soils, respectively. Median supplies for households in expenditure quintile 5 were approximately 3-4 fold greater than those in expenditure quintile 1 on both soil types.

Using local composition data and $24 \mathrm{~h}$ dietary recall, Eick et al. [21] estimated mean dietary supply of Se to be 44 and $46 \mu \mathrm{g}$ capita $^{-1} \mathrm{~d}^{-1}$ in Mangochi District among tuberculosis patients $(n=40)$ and controls $(n=40)$. In the present study, estimated median (Q1, Q3) Se supplies of rural households in Mangochi District were $39(22,71) \mu$ capita $^{-1} \mathrm{~d}^{-1}$ on calcareous soils $(n=80)$ and $30(19,48) \mu$ capita $^{-1} \mathrm{~d}^{-1}$ on non-calcareous soils $(n=206)$.

Hurst et al. [22] estimated median dietary Se supplies of adult women in villages on calcareous Eutric Vertisols $(n=55)$ and non-calcareous $(n=58)$ soils to be 55 and $7 \mu \mathrm{g}$ capita $^{-1} \mathrm{~d}^{-1}$, respectively, based on mineral analyses of weighed duplicate diet composites. In the present study, median Se consumption per AME was 36.4 and $20.4 \mu \mathrm{g} \mathrm{d}^{-1}$ on calcareous and non-calcareous soils, respectively. The greater difference in dietary Se supplies between soil types found by Hurst et al. [22] is likely to be due to the subset of calcareous and noncalcareous soils that were sampled. For example, the median Se concentration of maize grain from Eutric Vertisols was $>0.3 \mathrm{mg} \mathrm{kg}^{-1}[22,27]$, approximately $10-$ fold greater than the median $\mathrm{Se}$ concentration of maize grain samples collected nationally from areas of calcareous soils used in the present study (median = $0.03 \mathrm{mg} \mathrm{kg}^{-1}, n=50$, Additional file 1: Table S5 and Additional file 1: Table S7). Eutric Vertisols, which cover $\sim 0.5 \%$ of the land area of Malawi, are a subset of the calcareous soil grouping and might provide greater concentrations of phyto-available Se than other calcareous soils. The non-calcareous villages selected by Hurst et al. [22] were not in a lakeshore EPA and low fish consumption may contribute to these extremely low Se supplies.

\section{Zinc}

Previously, Wessells and Brown [5] estimated mean national dietary Zn supply to be $8.3 \mathrm{mg}$ capita ${ }^{-1} \mathrm{~d}^{-1}$ based on 2003-2007 FBS data and regional or international composition data while Joy et al. [9] used 2009 FBS data to estimate $11.8 \mathrm{mg}$ capita $^{-1} \mathrm{~d}^{-1}$, and subsequently, using locally-generated composition data, 12.0 and $10.1 \mathrm{mg}$ capita $^{-1} \mathrm{~d}^{-1}$ on calcareous and non-calcareous soils, respectively [18]. Kumssa et al. [10] estimated mean Zn supply for Malawi to be $14.1 \mathrm{mg}$ capita $^{-1} \mathrm{~d}^{-1}$ on the basis of 2011 FBS data and US food composition data. VerduzcoGallo et al. [30] reported mean national dietary supplies of $\mathrm{Zn}$ to be $10.8 \mathrm{mg}_{\text {capita }}{ }^{-1} \mathrm{~d}^{-1}$ based on household survey data and regional or international composition data. Similar estimates were found in the present study, with mean and median $\mathrm{Zn}$ supplies of 10.4 and $8.5 \mathrm{mg}$ capita $^{-1} \mathrm{~d}^{-1}$ for all households and a median of 9.5 and $7.8 \mathrm{mg}$ capita $^{-1} \mathrm{~d}^{-1}$ for rural households on calcareous and non-calcareous soils, respectively. However, Siyame et al. [23] reported much lower dietary $\mathrm{Zn}$ supplies on the basis of duplicate diet composites, i.e. 6.4 and $4.8 \mathrm{mg} \mathrm{capita}^{-1} \mathrm{~d}^{-1}$ for women living on calcareous and non-calcareous soils, respectively. The villages studied by Siyame et al. [23] were not in lakeshore EPAs and low fish consumption might contribute to the very low $\mathrm{Zn}$ supplies in both the calcareous and non-calcareous areas.

The estimated prevalence of inadequate dietary $\mathrm{Zn}$ supplies in the current study is $57 \%$ nationally, and 49 and $62 \%$ for rural households on calcareous and non-calcareous soils, respectively. A high prevalence of inadequate $\mathrm{Zn}$ supplies has previously been estimated using FBS data, i.e. $41 \%$ nationally [5], $64 \%$ nationally [9], and 31 and $57 \%$ on calcareous and non-calcareous soils [18]; and IHS3 data, i.e. $54 \%$ for rural households [30].

Disease burden due to $\mathrm{Zn}$ deficiency was quantified for Malawi and other nations in the IHME Global Burden of Disease study on the basis of dietary $\mathrm{Zn}$ supplies $[5,7]$. Thus, a $41 \%$ national prevalence of inadequate dietary Zn supplies was estimated to cause 791 DALYs $(100 \mathrm{k} \text { population })^{-1}$ [51]. By extension, disease burden is likely to be $>1000$ DALYs (100 k population $)^{-1}$ for rural households on non-calcareous soils where the prevalence of inadequate dietary $\mathrm{Zn}$ supplies was $62 \%$ (Additional file 1: Table S20).

\section{Phytate}

Previously, Wessells and Brown [5] estimated mean national dietary PA supply to be $2584 \mathrm{mg}$ capita $^{-1} \mathrm{~d}^{-1}$ with a PA:Zn molar ratio of 31 based on 2003-2007 FBS data and regional or international composition data while Joy et al. [9] used 2009 FBS data to estimate mean supply of $4510 \mathrm{mg}$ capita $^{-1} \mathrm{~d}^{-1}$ and a PA:Zn of 38 . Kumssa et al. [10] estimated mean PA supply of $3969 \mathrm{mg}$ capita $^{-1} \mathrm{~d}^{-1}$ and a PA:Zn molar ratio of 28 based on 2011 FBS data. The present study found mean and median PA supplies of 2795 and $2281 \mathrm{mg}$ capita $^{-1} \mathrm{~d}^{-1}$ with a mean PA:Zn molar ratio of 29. These estimates are closer to the Wessells and Brown [5] values owing to the adjustment in PA concentrations made due to milling.

The combination of a high prevalence of inadequate dietary $\mathrm{Zn}$ supplies and PA:Zn molar ratios $>15$ suggest that $\mathrm{Zn}$ deficiency is likely to be widespread in Malawi. This is consistent with anthropometric data, e.g. Gibson and Huddle [20] reported 36 and $46 \%$ prevalence of low plasma and hair $\mathrm{Zn}$ concentrations, respectively, among pregnant women in a rural area, and Siyame et al. [23] 
reported $>90 \%$ prevalence of $\mathrm{Zn}$ deficiency defined as plasma $\mathrm{Zn}<10.7 \mu \mathrm{mol} \mathrm{L}^{-1}$ among women living in rural areas on calcareous and non-calcareous soils. High dietary PA supplies might also increase the risks of $\mathrm{Ca}$ and $\mathrm{Mg}$ deficiencies due to inhibition of absorption [67, 68].

\section{Inadequate supplies of multiple elements}

Nationally, the prevalence of inadequate dietary supplies were greatest for $\mathrm{Ca}$, Se and $\mathrm{Zn}$. High dietary PA supplies are likely to increase risks of $\mathrm{Ca}$ and $\mathrm{Zn}$ deficiencies. Adequacy of dietary I supply is highly dependent on the concentration of $\mathrm{I}$ in salt and Fe deficiency is contingent on individuals' health, especially gut health and malaria. Thus, estimating the prevalence of I and $\mathrm{Fe}$ deficiencies based on food consumption data available in the IHS3 is problematic. Among rural households living on non-calcareous soils, concurrent dietary inadequacies of $\mathrm{Ca}$, Se and $\mathrm{Zn}$ occurred in $81 \%$ of households in expenditure quintile 1 compared to $15 \%$ of households in expenditure quintile 5 (Table 4). Of the 5156 households nationally that had adequate energy supplies to meet requirements, 30, 56 and $27 \%$ still had inadequate

Table 4 Inadequate dietary supplies of multiple elements

\begin{tabular}{|c|c|c|c|c|c|c|c|}
\hline \multirow[t]{3}{*}{ Urban/rural } & \multirow[t]{3}{*}{$\begin{array}{l}\text { Soil } \\
\text { type }\end{array}$} & \multirow[t]{3}{*}{$\begin{array}{l}\text { Expenditure } \\
\text { quintile }\end{array}$} & \multirow[t]{3}{*}{$n$} & \multicolumn{4}{|c|}{$\begin{array}{l}\text { Households with ' } x \text { ' concurrent } \\
\text { inadequate intakes }\end{array}$} \\
\hline & & & & 0 & 1 & 2 & 3 \\
\hline & & & & \multicolumn{4}{|c|}{$\%$} \\
\hline \multirow[t]{5}{*}{ Urban } & \multirow[t]{5}{*}{3} & 1 & 57 & 7 & 4 & 23 & 67 \\
\hline & & 2 & 135 & 9 & 14 & 30 & 47 \\
\hline & & 3 & 228 & 11 & 11 & 36 & 42 \\
\hline & & 4 & 442 & 21 & 15 & 32 & 32 \\
\hline & & 5 & 1311 & 45 & 16 & 21 & 17 \\
\hline \multirow[t]{15}{*}{ Rural } & \multirow[t]{5}{*}{1} & 1 & 493 & 6 & 8 & 24 & 62 \\
\hline & & 2 & 450 & 19 & 16 & 24 & 41 \\
\hline & & 3 & 385 & 30 & 17 & 24 & 29 \\
\hline & & 4 & 379 & 52 & 17 & 16 & 15 \\
\hline & & 5 & 340 & 68 & 14 & 10 & 9 \\
\hline & \multirow[t]{5}{*}{2} & 1 & 1000 & 2 & 3 & 14 & 81 \\
\hline & & 2 & 1297 & 6 & 9 & 23 & 62 \\
\hline & & 3 & 1424 & 11 & 12 & 27 & 49 \\
\hline & & 4 & 1467 & 19 & 19 & 28 & 34 \\
\hline & & 5 & 1335 & 44 & 23 & 18 & 15 \\
\hline & \multirow[t]{5}{*}{3} & 1 & 290 & 3 & 7 & 18 & 72 \\
\hline & & 2 & 291 & 10 & 12 & 27 & 51 \\
\hline & & 3 & 294 & 20 & 19 & 30 & 31 \\
\hline & & 4 & 294 & 29 & 22 & 30 & 19 \\
\hline & & 5 & 205 & 54 & 22 & 14 & 9 \\
\hline
\end{tabular}

Concurrent inadequate dietary supplies of calcium, selenium and zinc at household level by urban/rural location, expenditure quintile $(1=$ poorest, $5=$ highest $)$ and soil type ( $1=$ calcareous; $2=$ non-calcareous; $3=$ undifferentiated $)$ supplies of $\mathrm{Ca}$, Se and $\mathrm{Zn}$, respectively, to meet sum of member EARs, while $16 \%$ had concurrent inadequate supplies of all three elements.

\section{Interventions to improve dietary micronutrient supplies} Strategies to improve dietary micronutrient supplies include direct supplementation, food-based interventions (such as fortification of cereal flours at the processing stage or dietary diversification), and agricultural interventions (such as biofortification of crops through breeding or application of micronutrient-enriched fertilisers). Recently, it was demonstrated that agronomic biofortification of staple cereals may be a cost-effective strategy to reduce dietary $\mathrm{Zn}$ deficiencies in Malawi if $\mathrm{Zn}$ is delivered via foliar sprays, although such a strategy is likely to be less cost-effective than biofortification via crop breeding [69]. Here, two other scenarios are explored: the iodisation of salt and agronomic biofortification of maize grain with Se.

Over 99 \% of households in Malawi were not consuming adequate I through foods other than salt to meet requirements. However, the I status of Malawi has recently been defined as 'adequate' based on UIC of school-aged children [62]; thus it is likely that salt iodisation has already been a considerable success. Yet challenges remain. The WHO recommend that adults consume $<5 \mathrm{~g} \mathrm{~d}^{-1}$ of salt to limit risk of chronic disease due to excessive sodium intakes [70, 71], yet the IHS3 data shows median salt supply per AME of $11.2 \mathrm{~g} \mathrm{~d}^{-1}$. Even with universal coverage of salt iodised at the recommended $15 \mathrm{mg} \mathrm{kg}^{-1}$ and individual consumption of salt of $5 \mathrm{~g} \mathrm{~d}^{-1}, 93 \%$ of households in Malawi would have inadequate I supply to meet dietary requirements. The prevalence of inadequate dietary I supply would be 24 and $<1 \%$ if salt consumption were 7.5 and $10 \mathrm{~g}$ capita $^{-1} \mathrm{~d}^{-1}$, respectively. Alternatively, iodising salt at $30 \mathrm{mg} \mathrm{kg}{ }^{-1}$ would supply adequate I to $99 \%$ of households if individual consumption of salt was $5 \mathrm{~g} \mathrm{~d}^{-1}$.

Salt iodisation programmes need close monitoring. Iodisation of table salt is mandatory in Malawi yet only $62 \%$ of households in Malawi were consuming adequately iodised salt in 2010 [61] suggesting problems with compliance or losses due to improper storage. A recent spot survey of adult women in Malawi living on calcareous $(n=59)$ and non-calcareous soils $(n=59)$ found that the median creatinine-corrected UIC was $203 \mu \mathrm{g} \mathrm{L} \mathrm{L}^{-1}$. However, there was a $14 \%$ prevalence of I deficiency (UIC $<100 \mu \mathrm{g} \mathrm{L}^{-1}$ ) but $21 \%$ prevalence of excess (UIC >300 $\mu \mathrm{g} \mathrm{L}^{-1}$ ) [48]. Thus, high household salt supplies or I concentration in salt might be contributing to excessive I intakes, risking hypo- and hyper-thyroidism.

An agronomic biofortification programme for Se in Malawi could be effective without major changes in farm-level infrastructure through enrichment of existing 
fertilisers applied to maize [72-74]. Addition of $10 \mathrm{~g}$ Se $\mathrm{ha}^{-1}$ via a granular NPK fertiliser to maize grown on different soils in Malawi achieved a mean concentration of $0.276 \mathrm{mg} \mathrm{Se} \mathrm{kg}^{-1}$ in the grain [72] which is $\sim 18$-fold greater than the median Se concentration of maize grain samples from non-calcareous soils used in the present study. The approach has precedents, having largely eliminated dietary Se deficiency in Finland [75] and may be effective via a range of cereal crops [75-77]. Biofortification of staple crops has the potential to be highly equitable as staple foods are consumed on a daily basis by most low-income households and individuals with low status within the household. For example, $98 \%$ of all households in IHS3 and $94 \%$ of those in expenditure quintile 1 reported consuming maize. Furthermore, alternative options to increase dietary element supplies are limited in subsistence contexts. For example, Fiedler et al. [78] showed that flour fortification during milling currently has limited reach in Zambia as few households purchase maize flour from large, centralised milling factories and those that do are generally wealthier with greater baseline $\mathrm{Zn}$ intakes.

Application of Se increases its concentration in all fractions of the grain including the endosperm [79], although concentration is likely to be greater in the bran and embryo and previously it was demonstrated that refined maize flour has $\sim$ half the concentration of Se than the whole grain (Additional file 1: Table S6). Thus, if all maize grown on non-calcareous soils received $10 \mathrm{~g}$ Se $\mathrm{ha}^{-1}$, the median concentration of 'Maize $u f a$ refined

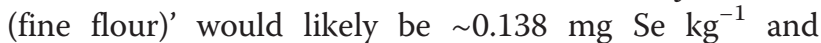
maize products would supply $\sim 37 \mu \mathrm{g}$ Se capita $^{-1} \mathrm{~d}^{-1}$ compared to $\sim 4 \mu \mathrm{g}$ Se capita ${ }^{-1} \mathrm{~d}^{-1}$ without biofortification. The prevalence of inadequate dietary Se supplies among rural households on non-calcareous soils would fall from 82 to $14 \%$. However, the efficacy will depend on fertiliser use. Currently, maize production in Malawi requires $\sim 140 \mathrm{kt}$ of fertiliser nitrogen $(\mathrm{N})$ to cover the $\sim 2800$ kha of production [69]. Usage is $\sim 50$ kt (i.e. $36 \%$ of requirement) of which $\sim 35 \mathrm{kt}$ is subsidised under the Farm Input Subsidy Programme (FISP) [80]. Thus, the efficacy of a biofortification scenario is likely to be $\sim 36 \%$ of the universal application modelled above, i.e. reducing prevalence of inadequate dietary Se supplies from 82 to $57 \%$.

Agronomic biofortification with Se in areas where dietary deficiency occurs is likely to be highly costeffective. If maize production in Malawi is assumed to be evenly distributed across different soil types then there are $\sim 2000$ kha of maize production on noncalcareous soils [69]. Application of $10 \mathrm{~g} \mathrm{ha}^{-1}$ of Se would therefore cost US\$ $\sim 2$ million year ${ }^{-1}$, assuming exogenous Se costs US\$ $100 \mathrm{~kg}^{-1}$ (other programmatic costs not included). Thus, for application of $\mathrm{Se}$ at
$10 \mathrm{~g} \mathrm{ha}^{-1}$, a percentage point drop in national dietary Se deficiency prevalence would cost $\sim$ US $\$ 27,000 \mathrm{yr}^{-1}$. If the Se status of individuals is assumed to be the same as their respective household status, then the cost per alleviated case of dietary Se deficiency would be $\sim$ US\$ $0.36 \mathrm{year}^{-1}$. The WHO TUL of intake for Se is $400 \mu \mathrm{g} \mathrm{d}^{-1}$ for adults and excessive Se intake may be defined as household supply per AME $>400 \mu \mathrm{g} \mathrm{d}^{-1}$. With universal application of $10 \mathrm{~g} \mathrm{ha}^{-1}$ of Se on noncalcareous soils, 13 out of 12,117 households $(\sim 0.1 \%)$ would be expected to have excessive Se intake. The actual risk of excessive intakes is likely to be lower as all of these 13 households reported consuming $>4000$ kcal per AME $\mathrm{d}^{-1}$ which is implausibly high over a long period. Cost-effectiveness could be improved if Se-enriched fertiliser was distributed through the FISP scheme due to the greater prevalence of inadequate dietary Se supplies among poorer households. Furthermore, the modelled scenarios are likely to underestimate efficacy due to increases in the Se concentration of legumes intercropped with maize and of livestock products fed on maize stover or grain receiving Seenriched fertiliser. Alfthan et al. [75] reported an increase in the contribution of animal products to human dietary Se intakes in Finland following a national policy of agronomic biofortification with Se; milk products from 'conventional' production had $\sim 2$-fold greater Se concentration than from 'organic' production. There may also be benefits to livestock productivity and health [81] which are not captured in the current study.

\section{Use of household surveys to estimate the prevalence of inadequate dietary element supplies in Malawi}

There are three main potential sources of dietary survey data: individual-level recall, household-level surveys and national-level FBSs. Individual-level $24 \mathrm{~h}$ diet recall is considered the 'gold standard' for dietary assessment by nutritionists, but the approach is often prohibitively expensive to conduct at large scales e.g. nationally [82] and only small-scale surveys have been conducted in Malawi. Household surveys and FBSs are routinely conducted/compiled allowing longitudinal assessment of diets at national, e.g. [30], or international scales, e.g. [10, 49]. The main advantage of household surveys over FBSs is that they provide insights into the distribution of element supplies at sub-national levels. In the present study, there was a positive skew in the distribution of household supplies of all nutrients (Fig. 7). Thus, $68 \%$ of households had per capita supplies of Ca less than the mean of all households, i.e. $924 \mathrm{mg} \mathrm{capita}^{-1} \mathrm{~d}^{-1}$. Estimates of dietary element supplies derived from FBSs have previously assumed a normal distribution of individual-level dietary supplies centred on mean per capita availability of an element in the national food supply; a 'cut-point' is set as 

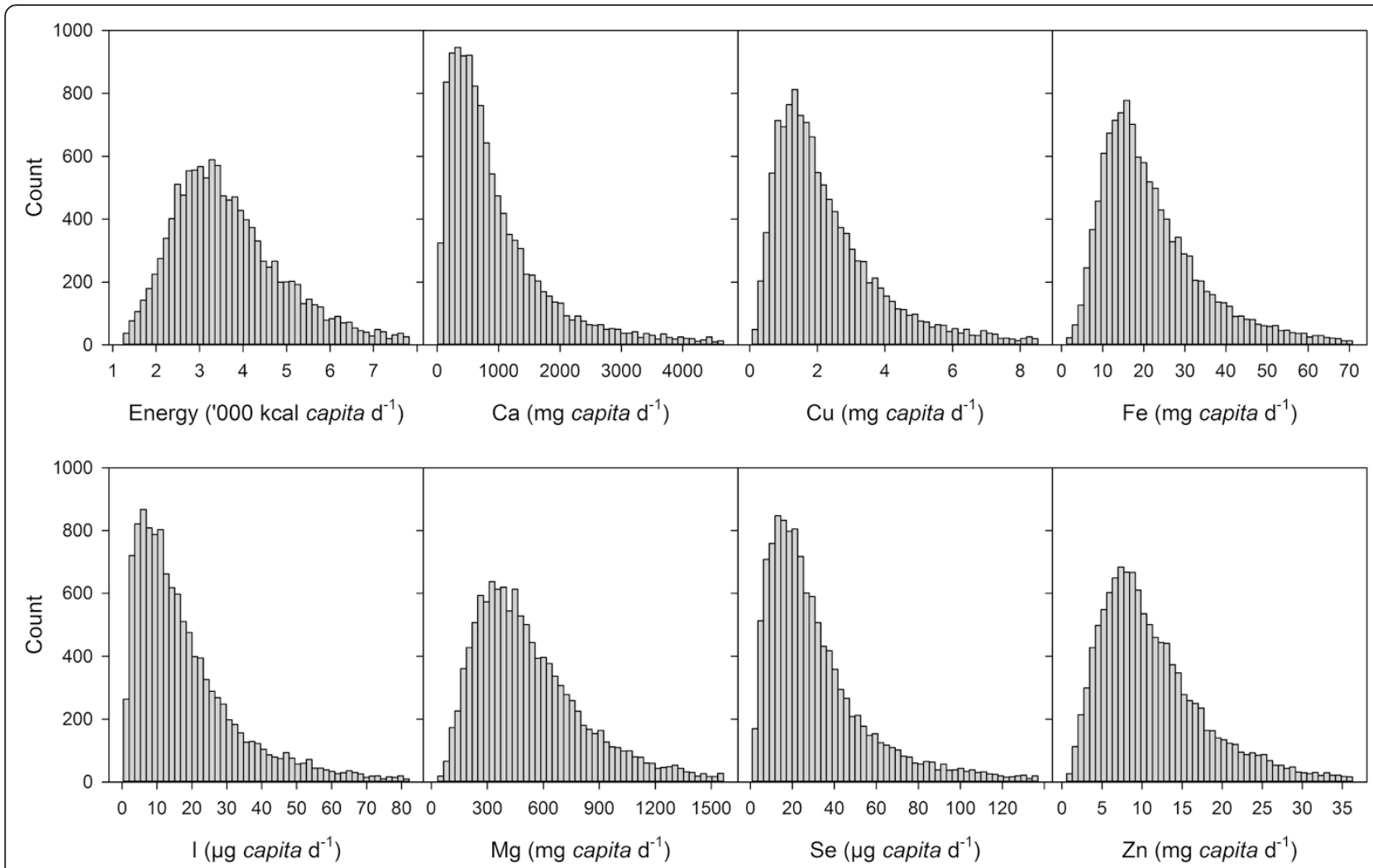

Fig. 7 Distribution of household nutrient supplies. Dietary supplies of energy, calcium (Ca), copper (Cu), iron (Fe), iodine (I), magnesium (Mg), selenium (Se) and zinc ( $\mathrm{Zn})$. lodine supply excludes salt

the national mean EAR and prevalence of inadequate supplies is assumed to equal the proportion of the population with intakes below this level $[5,9]$. If the positive skew in household level supplies also occurred at individual level, then the FBS approach is likely to underestimate the prevalence of inadequate dietary supplies.

There are three further advantages of deriving food consumption data from the IHS3 compared to the Malawi FBS. First, a greater variety of food items or break down of major food items are reported than the standard 94 edible items in the FBS, for example common indigenous vegetables, or refined and whole grain maize flour, and this allows more accurate matching of crop composition data. Second, FBSs generally rely on crop or livestock production data which may be restricted to commercialised major food crops; for example, sweet potato supply is not recorded in the most recent FBS [57]. Third, IHS3 gives insights into seasonality of supplies.

National-level estimates of inadequate dietary supplies derived from the analysis of FBSs might spur policy makers to intervene or support further research. However, inter-household and seasonal variation in food choice and dietary micronutrient intakes are likely to be required for effective policy making. For example, agronomic biofortification appears to be a promising strategy to address dietary Se deficiency in Malawi [22, 72-74]. A policy maker might question whether an intervention needs to reach wealthy households with their greater calorie intakes and more diverse diets. Despite greater consumption of nutrient-dense foods including fish, $55 \%$ of households in expenditure quintile 5 on non-calcareous soils had inadequate Se supplies to meet sum of member EARs. Thus, enriching subsidised fertiliser used by poorer households would not be sufficient in eliminating dietary Se deficiency. Valid concerns of potential toxicity might also be raised given the relatively narrow range between 'inadequate' and 'excessive' intakes of Se [40]; but in the present study, it was estimated that $\sim 0.1 \%$ of the population would have excessive intakes if application of Se at $10 \mathrm{~g} \mathrm{ha}^{-1}$ were universal on non-calcareous soils. And this figure is likely to be lower if households with unrealistically high calorie intakes are removed. Similarly, Fiedler et al. [78] used household survey data to address concerns over the effectiveness and safety of potential food fortification schemes in Zambia. However, close monitoring of fertiliser enrichment and distribution to appropriate areas would be required, similar to management considerations in the salt iodisation strategy. 


\section{Caveats}

\section{Dietary recall at household level}

Dietary recall provides a proxy for food consumption and is subject to error. Recall error can occur when interviewees forget instances of food consumption ('recall loss') or include items which were consumed prior to the recall period ('telescoping errors'). These types of error are likely to be greater for longer recall periods. Furthermore, the ability of one household member to accurately report the consumption of all household members is questionable, and this might account for some of the association between decreasing dietary energy supplies with increasing household size (Fig. 3). Under- or over-reporting of food consumption can also be intentional. For example, respondents in the UK and US national dietary surveys were estimated to underreport their individual calorie intakes by up to $41 \%$ [83, 84]. This occurred in a society in which being overweight is generally perceived as undesirable, yet in the UK 71 and $58 \%$ of men and women, respectively, have a Body Mass Index >25 [46].

Social pressures in Malawi are likely to differ to those in the UK or US. For example, being overweight is generally perceived as healthy and socially desirable [85] and it is interesting to note the high reported calorie consumption of the wealthiest expenditure quintile, i.e. mean and median consumption per AME of 3837 and $3618 \mathrm{kcal} \mathrm{d}^{-1}$ compared to a requirement of $3300 \mathrm{kcal} \mathrm{d}^{-1}$ for adult males with a PAL of 1.9. Also, many wealthy individuals, particularly in urban areas, are unlikely to require such high calorie intakes due to lower PALs. For example, an adult male with a sedentary or light activity level would require $2500-3000 \mathrm{kcal} \mathrm{d}^{-1}$ [38].

In addition to recall errors, there are likely to be numerous reporting errors introduced by enumerators. The capping of food item consumption at maximum plausible levels is likely to have reduced, though not eliminated, the influence of such errors. Local units are a convenient way to report quantities consumed in an interview process but may encourage inaccurate reporting. For example, $\sim 80 \%$ of households that recorded consumption of the food item 'Maize ufa refined (fine flour)' expressed the quantity consumed in units of small, medium or large pails. The accuracy of these units is subject to the interpretation of the interviewees and enumerators, as well as the conversion to metric units applied by the authors of the present study.

One quick way to assess the validity of food consumption data reported in the IHS3 is to look at the plausibility of dietary energy supplies. As reported in the Results, there were both implausibly low and high calorie intakes when households were aggregated at the EPA level. The energy requirement of an adult male with PAL of 1.9 and body mass of $70 \mathrm{~kg}$ is $\sim 3300 \mathrm{kcal} \mathrm{d}^{-1}$ [38], yet $21 \%$ of households reported consumption per AME of $<1650 \mathrm{kcal} \mathrm{d}^{-1}$, i.e. half the requirement, and $8 \%$ reported $>4950 \mathrm{kcal} \mathrm{d}^{-1}$, i.e. double the requirement, and these levels are highly unlikely to be sustainable for periods of more than a few days. If these households were excluded, the estimated national prevalence of inadequate dietary energy, $\mathrm{Ca}, \mathrm{Cu}$, Fe, I, Mg, Se and Zn supplies from foods other than salt would be $50,44,2,10,100,1,72$ and $51 \%$, respectively, compared to $57,49,6,18,99,5,74$ and $57 \%$ prior to removal of households with 'implausible' dietary energy intakes. Thus, the results of the present study are reasonably robust against recall or reporting errors at a national scale and demonstrated some regional variation that could not be identified using national-level food supply data, e.g. greater Ca supplies in lakeshore EPAs. However, taking Ca as an example, removing households with implausible energy intakes would increase or decrease the prevalence of inadequate dietary supplies by $>25 \%$ in 94 of 149 EPAs which suggests that further research is required to improve the accuracy of household survey food consumption data before intervention policies can be designed at the highly disaggregated level of the EPA.

Comparison between food supply in FBS and IHS3 reveals some consistencies and discrepancies. For example, mean national consumption of maize is reported as $365 \mathrm{~g} \mathrm{capita}^{-1} \mathrm{~d}^{-1} \mathrm{FW}$ in the 2009 FBS [57], equiva-

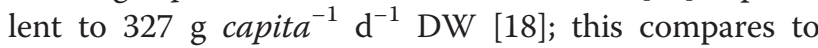
mean $( \pm \mathrm{SD})$ consumption of maize products (i.e. item codes 101-105 and 820) of $320( \pm 203)$ g capita $^{-1} \mathrm{~d}^{-1}$ DW in the household survey. However, mean consumption of freshwater fish differs by $\sim 7$-fold between the two food supply datasets ( $c f$. discussion on Ca supplies). The original source of FBS fish supply data in Malawi is not publicly available which prevents further investigation of this discrepancy.

The present study estimated dietary element supplies and prevalence of inadequate supplies at the household level due to the availability of data in the IHS3. However, intra-household variation in foods consumed is not captured. Energy requirement ratios of household members could be used to estimate distribution of foods within the household and hence the prevalence of inadequate supplies at the individual level. However, the reliability of this approach is questionable as it requires the assumption that all members within a household consume the same mixture of food items [86].

Estimating dietary supplies at household level is likely to underestimate the prevalence of inadequate intakes at individual levels because poorer, rural households are more likely to have inadequate dietary element supplies and to have larger household size (Tables 1 and 2; Additional file 1: Table S9 and Additional file 1: Table S10). If all individuals living in households with 
supplies less than sum of member EARs were assumed to have inadequate intakes, then the prevalence of dietary energy, $\mathrm{Ca}, \mathrm{Cu}, \mathrm{Fe}, \mathrm{I}, \mathrm{Mg}$, Se and $\mathrm{Zn}$ deficiencies among individuals would be 61, 53, 7, 20, $99,6,77$ and $63 \%$, respectively, compared to 57,49 , $6,18,99,5,74$ and $57 \%$ among households.

\section{Food composition}

As with food supply data, there is an accuracy-cost trade-off in the use of food composition data and caveats regarding composition data were discussed previously [18]. In the present study, households were assigned to 'calcareous', 'non-calcareous' and 'undifferentiated' soil types on the basis of their location. This is likely to improve the relevance of matched food composition data. A national-scale food crop survey can only capture some of the variation in crop composition due to soil factors or varietal differences. However, locallygenerated data remain preferable to the use of regionally or internationally collated datasets, particularly for elements such as Se where plant uptake is under strong geochemical control. However, it is inevitable that some households were misclassified due to GPS location being aggregated at EA level and displaced to ensure confidentiality or due to the resolution of soil maps.

\section{Nutrient requirements}

Nutrient requirements for age and sex categories are reported by a number of different public health bodies. In the present study, requirements were derived from FAO [38], WHO [39], and IOM [40, 41] as described in the Methods. However, aggregated requirement values cannot fully capture inter-individual variation in requirements, e.g. due to different body sizes, activity levels, presence of infection, consumption of promoters or inhibitors of nutrient absorption etc. A preference for conservative (i.e. high) requirement values might overestimate the prevalence of nutrient deificiencies.

\section{Drinking water}

Drinking water can contribute significantly to dietary element intakes but this was not quantified in the present study; consequently, the prevalence of inadequate dietary supplies may be overestimated. For example, an ad hoc survey of borehole waters $(n=19)$ revealed mean and median Ca concentration of 39.2 and $22.2 \mathrm{mg} \mathrm{L}^{-1}$ (range 3.2-209.3), I concentration of 15.4 and $12.6 \mu \mathrm{g} \mathrm{L}^{-1}$ (range 1.0-54.2) and $\mathrm{Mg}$ concentration of 31.4 and $24.8 \mathrm{mg} \mathrm{L}^{-1}$ (range 0.9-95.2; Additional file 1: Table S28). Mean concentrations of $\mathrm{Cu}, \mathrm{Fe}, \mathrm{Se}$ and $\mathrm{Zn}$ were 1.9, 0.3, 0.2 and $8.4 \mu \mathrm{g} \mathrm{L}^{-1}$ which is insignificant compared to dietary food intakes. A wider survey would be required to assess the contribution of drinking water to dietary element supplies, although this does illustrate the potential of some drinking waters to contribute significantly to dietary $\mathrm{Ca}, \mathrm{Mg}$ and I supplies as seen in other contexts, e.g. $[87,88]$.

\section{Conclusions}

Prevalence of dietary element supplies and deficiencies were quantified for Malawi by combining food consumption data captured in the most recent household survey (IHS3) with locally-generated food composition data, stratified by soil type. We estimate that $57 \%$ of households had inadequate dietary energy supplies for requirements of an active lifestyle, while $>50 \%$ of households had inadequate dietary supplies of $\mathrm{Ca}$, Se or $\mathrm{Zn}$ to meet requirements but $<20 \%$ had inadequate dietary supplies of $\mathrm{Cu}, \mathrm{Fe}$ and $\mathrm{Mg}$. Among households with adequate energy supply, 30, 56 and $27 \%$ still had inadequate supplies of $\mathrm{Ca}, \mathrm{Se}$ and $\mathrm{Zn}$ to meet requirements. Supply of I from foods other than salt is inadequate for $>99 \%$ of households. Access to essential nutrients varied due to socioeconomic and environmental factors. For example, the median supply of $\mathrm{Ca}$ in rural households in the wealthiest and poorest expenditure quintiles was 1157 and $255 \mathrm{mg}$ capita $^{-1} \mathrm{~d}^{-1}$, respectively; the difference was largely driven by the consumption of fish with a median supply of Ca from fish of 737 and $246 \mathrm{mg}$ capita $^{-1} \mathrm{~d}^{-1}$ in the wealthiest and poorest expenditure quintiles, respectively. The median supply of Se among rural households in areas of calcareous and non-calcareous soil was 30.7 and $17.3 \mu \mathrm{g}$ capita $^{-1} \mathrm{~d}^{-1}$, respectively; the difference was driven by food composition, with median Se concentration of 0.0138 and $0.0071 \mathrm{mg} \mathrm{kg}^{-1}$ in refined maize flour from calcareous and non-calcareous soils, respectively.

Nationally, cereals supplied $>60 \%$ of dietary energy, $>40 \%$ of $\mathrm{Mg}$ and $\mathrm{Zn},>30 \%$ of Fe and $>20 \%$ of Se, but $<5 \%$ of $\mathrm{Ca}$. Fish was an essential source of micronutrients for many households, partly due to the preference for eating whole small fish (usipa) including bones. Overall, $77 \%$ of households recorded fish consumption during 7 days preceding their interview, and fish supplied 62, 47 and $26 \%$ of national dietary $\mathrm{Ca}$, Se and $\mathrm{Zn}$ supplies. However, consumption of fish varies with greater access for wealthier households and those living in lakeshore EPAs.

Two strategies to increase dietary element supplies were modelled. We show that iodisation of salt at 15-30 mg kg-1 can ensure that the majority of households have adequate I supplies due to near universal consumption of salt, including in poorer, rural households. However, mean household salt supplies of $11.2 \mathrm{~g}$ per AME were greater than the WHO maximum recommended intake of $5 \mathrm{~g} \mathrm{capita}^{-1} \mathrm{~d}^{-1}$ and close monitoring of iodisation levels at production is required to avoid excessive I intakes. Agronomic biofortification with $10 \mathrm{~g} \mathrm{Se} \mathrm{ha}^{-1}$ of maize has the potential to reduce the prevalence of 
inadequate dietary Se supplies from 82 to $14 \%$ of households living on non-calcareous soils, and from 95 to $21 \%$ for the poorest subset of those households. However, if only those fertilisers currently in use were enriched, the prevalence of inadequate Se intakes among all households living on non-calcareous soils would fall from 82 to $57 \%$ The cost per alleviated case of dietary Se deficiency would be $\sim$ US\$ 0.36 year $^{-1}$, representing a highly cost-effective strategy.

Household surveys provide a valuable resource for assessing national diets, although the accuracy of food consumption data remains an issue: instances of implausibly high or low reported energy intakes suggest reporting errors, possibly due to purposeful under- and over-reporting. Also, there are unresolved discrepancies between national-level FBS and household survey datasets, for example the $\sim 7$-fold greater estimated consumption of fish based on IHS3. The present study used food crop composition data generated for Malawi and demonstrated significant variation in dietary supplies of some elements depending on soil properties. However, locallygenerated food crop composition data stratified by soil type are not available for many countries. Thus, work to improve the accuracy and spatial resolution of food crop composition data is required to extend the methodology to other countries, particularly for elements where plant uptake is under strong geochemical control.

\section{Additional files}

Additional file 1: Tables S1 to S30 Joy et al. Tables S1 - S30 provide: supporting information regarding the integration of food supply and composition datasets; summaries of results by household environmental and socioeconomic factors; and summaries of results by Extension Planning Area (EPA). (XLSX $995 \mathrm{~kb}$ )

Additional file 2: Figure S1. Assignment of Enumeration Areas (EAs) to soil types. Soil type was assigned as 'calcareous' or 'non-calcareous' if more than two-thirds of the EA area was covered by one of these soil classes, except for large EAs ( $\geq 10,000 \mathrm{ha}$ ) for which soil type was assigned by laying a $5 \mathrm{~km}$ buffer around the modified household GPS point location. Soil series data from [43] and EPA boundaries from Ministry of Agriculture. (TIFF $748 \mathrm{~kb}$ )

\section{Abbreviations}

AME: adult male equivalent; Ca: calcium; Cu: copper; DALY: disability-adjusted life-year; DER: dietary energy requirement; DW: dry-weight; EA: Enumeration Area; EAR: estimated average requirement; EP: edible portion; EPA: Extension Planning Area; FAO: Food and Agriculture Organization of the United Nations; FBS: Food Balance Sheet; Fe: iron; FISP: farm input subsidy scheme; GPS: Geographical Position System; I: iodine; IHME: Institute of Health Metrics and Evaluation; IHS3: Third Integrated Household Survey of Malawi; IOM: Institute of Medicine; Mg: magnesium; N: nitrogen; PA: phytic acid; PAL: physical activity level; RNI: recommended nutrient intake; Se: selenium; UIC: urinary iodine concentration; WHO: World Health Organization; YLD: years of life lost due to disability; Zn: zinc.

\section{Competing interests}

Funding has previously been received by MRB, ADCC and SDY from Yara Fertilisers for Se-related research in UK and Malawi (2003-2011), but no industry funds were used in this study. The authors declare no other competing interests.

\section{Authors' contribution}

EJMJ, ELA, MRB and DBK conceived the study. EJMJ and DBK compiled the food supply data. EJMJ, MJW, ELA, SDY and ADCC generated the food composition data. EJMJ, DBK and ELA integrated the datasets. EJMJ and DBK drafted the manuscript and figures/tables, with input from all authors. All authors read and approved the final manuscript.

\section{Acknowledgements}

EJMJ's studentship is funded by the University of Nottingham, UK and the British Geological Survey. DBK's studentship is funded by the Crops For the Future Research Centre, University of Nottingham, Malaysia.

\section{Author details}

${ }^{1}$ School of Biosciences, University of Nottingham, Sutton Bonington Campus, Loughborough LE12 5RD, UK. ${ }^{2}$ Inorganic Geochemistry, Centre for Environmental Geochemistry, British Geological Survey, Keyworth, Nottingham NG12 5GG, UK. ${ }^{3}$ Crops For the Future, The University of Nottingham Malaysia Campus, Jalan Broga, 43500 Semenyih, Selangor Darul Ehsan, Malaysia. "Lunyangwa Research Station, Ministry of Agriculture, Irrigation and Water Development, Department of Agricultural Research, Mzuzu, Malawi.

Received: 12 May 2015 Accepted: 7 December 2015

Published online: 19 December 2015

\section{References}

1. Food and Agriculture Organization of the United Nations. The state of food security in the World: The multiple dimensions of food security. Rome: FAO; 2013

2. World Health Organization. Worldwide prevalence of anaemia 1993-2005. In: de Benoist B, McLean E, Egli I, Cogswell M, editors. WHO global database on anaemia. Geneva: WHO; 2008

3. World Health Organization. Global prevalence of vitamin A deficiency in populations at risk 1995-2005. WHO global database on vitamin A deficiency. Geneva: WHO; 2009.

4. Stein AJ. Global impacts of human mineral malnutrition. Plant Soil. 2010;335:133-54. doi:10.1007/s11104-009-0228-2.

5. Wessells KP, Brown KH. Estimating global prevalence of zinc deficiency: results based on zinc availability in national food supplies and the prevalence of stunting. PLoS One. 2012;7, e50568. doi:10.1371/journal.pone.0050568.

6. Andersson M, Karumbunathan V, Zimmermann MB. Global iodine status in 2011 and trends over the past decade. J Nutr. 2012;142:744-50. doi:10.3945/jn.111.149393

7. Lim SS, Vos T, Flaxman AD, Danaei G, Shiuya K, Adair-Rohani H, et al. A comparative risk assessment of burden of disease and injury attributable to 67 risk factors and risk factor clusters in 21 regions, 1990-2010: a systematic analysis for the Global Burden of Disease Study 2010. Lancet. 2012;380:2224-60. doi:10.1016/S0140-6736(12)61766-8.

8. Muthayya S, Rah JH, Sugimoto JD, Roos FF, Kraemer K, Black RE. The global hidden hunger indices and maps: An advocacy tool for action. PLoS One. 2013;8, e67860. doi:10.1371/journal.pone.0067860.

9. Joy EJM, Ander EL, Young SD, Black CR, Watts MJ, Chilimba ADC, et al. Dietary mineral supplies in Africa. Physiol Plantarum. 2014;151:208-29. doi:10.1111/ppl.12144.

10. Kumssa DB, Joy EJM, Ander EL, Watts MJ, Young SD, Walker S, et al. Dietary calcium and zinc deficiency risks are decreasing but remain prevalent. Sci Rep. 2015:5:10974. doi:10.1038/srep10974.

11. Combs GF. Selenium in global food systems. Br J Nutr. 2001;85:517-47.

12. Lyons GH, Genc Y, Stangoulis JCR, Palmer LT, Graham RD. Selenium distribution in wheat grain, and the effect of postharvest processing on wheat selenium content. Biol Trace Elem Res. 2005;103:155-68. doi:10.1385/BTER:103:2:155.

13. Broadley MR, Chilimba ADC, Joy EJM, Young SD, Black CR, Ander EL, et al. Dietary requirements for magnesium, but not calcium, are likely to be met in Malawi based on national food supply data. Int J Vitam Nutr Res. 2012:82:192-9. doi:10.1024/0300-9831/a000111.

14. Fairweather-Tait SJ, Bao Y, Broadley MR, Collings R, Ford D, Hesketh JE, et al. Selenium in human health and disease. Antioxid Redox Signal. 2011;14:1337-83. doi:10.1089/ars.2010.3275. 
15. Gibson RS, Hess SY, Hotz C, Brown KH. Indicators of zinc status at the population level: a review of the evidence. Br J Nutr. 2008;99:S14-23. doi:10.1017/S0007114508006818.

16. Stein AJ. Rethinking the measurement of undernutrition: Should we look at possible causes or actual effects? Global Food Secur. 2014;3:193-9. doi:10.1016/j.gfs.2014.09.003.

17. Sandström B. Dietary pattern and zinc supply. In: Mills CF, editor. Zinc in Human Biology. Devon, UK: Springer; 1989. p. 350-63.

18. Joy EJM, Broadley MR, Young SD, Black CR, Chilimba ADC, Ander EL, et al. Soil type influences crop mineral composition in Malawi. Sci Total Environ. 2015;505:587-95. doi:10.1016/j.scitotenv.2014.10.038.

19. Ferguson EL, Gibson RS, Weaver SD, Heywood P, Heywood A, Yaman C. The mineral content of commonly consumed Malawian and Papua New Guinean foods. J Food Compos Anal. 1989;2:260-72.

20. Gibson RS, Huddle JM. Suboptimal zinc status in pregnant Malawian women: its association with low intakes of poorly available zinc, frequent reproductive cycling, and malaria. Am J Clin Nutr. 1998;67:702-9.

21. Eick F, Maleta K, Govasmark E, Duttaroy AK, Bjune AG. Food intake of selenium and sulphur amino acids in tuberculosis patients and healthy adults in Malawi. Int J Tuberc Lung Dis. 2009;13:1313-5.

22. Hurst R, Siyame EWP, Young SD, Chilimba ADC, Joy EJM, Black CR, et al. Soiltype influences human selenium status and underlies widespread selenium deficiency risks in Malawi. Sci Rep. 2013;3:1425. doi:10.1038/srep01425.

23. Siyame EWP, Hurst R, Wawer AA, Young SD, Broadley MR, Chilimba ADC, et al. A high prevalence of zinc- but not iron-deficiency among women in rural Malawi: a cross-sectional study. Int J Vitam Nutr Res. 2013;83:176-87. doi:10.1024/0300-9831/a000158.

24. Dickinson N, Rankin J, Pollard M, Maleta K, Robertson C, Hursthouse A. Evaluating environmental and social influences on iron and zinc status of pregnant subsistence farmers in two geographically contrasting regions of Southern Malawi. Sci Total Environ. 2014;500-501:199-210. doi:10.1016/j.scitotenv.2014.08.087.

25. Gibson RS, Wawer AA, Fairweather-Tait SJ, Hurst R, Young SD, Broadley MR, et al. Dietary iron intakes based on food composition data may underestimate the contribution of potentially exchangeable contaminant iron from soil. J Food Compos Anal. 2015:40:19-23. doi:10.1016/j.ffa.2014.11.016.

26. Food and Agriculture Organization of the United Nations. Food Balance Sheets: a handbook. FAO, Rome, 2001. http://www.fao.org/docrep/003/ x9892e/x9892e00.htm. Accessed May 2013.

27. Chilimba ADC, Young SD, Black CR, Rogerson KB, Ander EL, Watts MJ, et al. Maize grain and soil surveys reveal suboptimal dietary selenium intake is widespread in Malawi. Sci Rep. 2011;1:72. doi:10.1038/srep00072.

28. National Statistics Office of the Republic of Malawi. Malawi Third Integrated Household Survey (IHS3). NSO, Zomba, Malawi and World Bank Living Standards and Measurements Surveys, 2012. http://econ.worldbank.org/ WBSITE/EXTERNAL/EXTDEC/EXTRESEARCH/EXTLSMS/0,"contentMDK: 23590235 pagePK:64168445 piPK:64168309 theSitePK:3358997,00.html. Accessed September 2013.

29. Ecker O, Qaim M. Analyzing nutritional impacts of policies: an empirical study for Malawi. World Dev. 2011;39:412-28.

30. Verduzco-Gallo I, Ecker O, Pauw K. Changes in food and nutrition security in Malawi: Analysis of recent survey evidence. Working Paper 06. Washington DC, USA: International Food Policy Research Institute; 2014

31. National Statistics Office of the Republic of Malawi. Malawi Third Integrated Household Survey: Household socioeconomic characteristics report. NSO, Zomba, Malawi, 2012. http://siteresources.worldbank.org/INTLSMS/Resources/ 3358986-1233781970982/5800988-1271185595871//HS3_Report.pdf. Accessed September 2013

32. World Bank. Living Standards Measurement Study: Malawi IHS3 Survey Data Availability. http://go.worldbank.org/DLFL1FPEP0. Accessed September 2013

33. National Statistics Office of the Republic of Malawi. Malawi Third Integrated Household Survey: Basic information document. NSO, Zomba, Malawi and World Bank Living Standards and Measurements Surveys, 2012. http:// siteresources.worldbank.org/INTLSMS/Resources/3358986-1233781970982/ 5800988-1271185595871/IHS3.BID.FINAL.pdf. Accessed September 2013.

34. Broadley MR, White PJ, Hammond JP, Zelko I, Lux A. Zinc in plants. New Phytol. 2007;173:677-702. doi:10.1111/j.1469-8137.2007.01996.x.

35. Yruela I. Copper in plants. Braz J Plant Physiol. 2005;17:1. doi:10.1590/S1677-04202005000100012.

36. Lukmanji Z, Hertzmark E, Mlingi N, Assey V, Ndossi G, Fawzi W. Tanzania food composition tables. Boston, USA; Tanzania: Harvard School of Public
Health, Boston, Muhimbili University College of Health and Allied Sciences, Dar es Salaam, Tanzania Food and Nutrition Center, Dar es Salaam; 2008.

37. United States Department of Agriculture, Agricultural Research Service. USDA National Nutrient Database for Standard Reference, Release 26, 2013. http://www.ars.usda.gov/Services/docs.htm?docid=24936. Accessed September 2014.

38. Food and Agriculture Organization of the United Nations. Human energy requirements. Report of a Joint FAO/WHO/UNU Expert Consultation. Rome: $\mathrm{FAO} ; 2001$.

39. World Health Organization and Food and Agriculture Organization of the United Nations. Vitamin and mineral requirements in human nutrition. Geneva: WHO; 2004.

40. Institute of Medicine of the National Academies. Dietary Reference Intakes for vitamin A, vitamin K, arsenic, boron, chromium, copper, iodine, iron, manganese, molybdenum, nickel, silicon, vanadium and zinc. Washington DC: National Academies Press; 2000.

41. Institute of Medicine of the National Academies. Dietary reference intakes for vitamin C, vitamin E, selenium, and carotenoids. Washington DC National Academies Press; 2002.

42. United Nations, Department of Economic and Social Affairs, Population Division. World Population Prospects: The 2012 Revision. http://esa.un.org/ unpd/wpp/Download/Standard/Population/. Accessed September 2014.

43. Green R, Nanthambwe S. Land Resources Appraisal of the Agricultural Development Divisions. Field Document No. 32. Ministry of Agriculture, UNDP, FAO: Lilongwe, Malawi. 1992.

44. Weisell R, Dop MC. The Adult Male Equivalent concept and its application to Household Consumption and Expenditures Surveys (HCES). Food Nutr Bull. 2012;33:S157-62.

45. Famine Early Warning System (FEWS NET). Malawi food security outlook update. June 2010. http://www.fews.net/sites/default/files/documents/ reports/Malawi_Outlook_January_2010_final.pdf. Accessed March 2015.

46. Public Health England and Food Standards Agency. National Diet and Nutrition Survey Results from Years 1, 2, 3 and 4 (combined) of the Rolling Programme (2008/2009 - 2011/2012). Bates B, Lennox A, Prentice A, Bates C, Page P, Nicholson S, Swan G, editors. Public Health England, London, 2014.

47. Diosady LL, Alberti JO, Venkatesh Mannar MG, FitzGerald S. Stability of iodine in iodized salt used for correction of iodine-deficiency disorders. II Food Nutr Bull. 1998;19:240-50.

48. Watts MJ, Joy EJM, Young SD, Broadley MR, Chilimba ADC, Gibson RS, et al. lodine source apportionment in the Malawian diet. Sci Rep. 2015;5:15251. doi:10.1038/srep15251.

49. Joy EJM, Young SD, Black CR, Ander EL, Watts MJ, Broadley MR. Risk of dietary magnesium deficiency is low in most African countries based on food supply data. Plant Soil. 2013;368:129-37. doi:10.1007/s11104-012-1388-z.

50. Kumssa DB, Joy EJM, Ander EL, Watts MJ, Young SD, Rosanoff A, et al. Global magnesium (Mg) supply in the food chain. Crop Pasture Sci. 2015;66. doi:10.1071/CP15096.

51. Institute for Health Metrics and Evaluation. Global Burden of Disease Study 2010. IHME, Seattle. http://ghdx.healthdata.org/record/global-burden-diseasestudy-2010-gbd-2010-results-risk-factor-1990-2010. Accessed July 2014.

52. Murray CJL, Vos T, Lozano R, Naghavi M, Flaxman AD, Michaud C, et al. Disability-adjusted life years (DALYs) for 291 diseases and injuries in 21 regions, 1990-2010: a systematic analysis for the Global Burden of Disease Study 2010. Lancet. 2012;380:2197-223. doi:10.1016/S0140-6736(12)61689-4.

53. Murray CJL. Quantifying the burden of disease: the technical basis for disability-adjusted life years. Bull World Health Organ. 1994;72:429-45.

54. Pauw K, Beck U, Mussa R. Did rapid smallholder-led agricultural growth fail to reduce rural poverty? Making sense of Malawi's poverty puzzle. A United Nations University WIDER Working Paper, 2014. https://www.wider.unu.edu/ publication/did-rapid-smallholder-led-agricultural-growth-fail-reduce-ruralpoverty. Accessed October 2014.

55. Engel E. Die produktions-und konsumptionsverhältnisse des königreichs Sachsen. Zeitschrift des Statistischen Bureaus des Königlich Sächsischen Ministerium des Inneren. 1857;8:1-54

56. Kaus W. Beyond Engel's law - A cross-country analysis. J Socio Econ. 2013; 47:118-34. doi:10.1016/j.socec.2013.10.001.

57. Food and Agriculture Organization of the United Nations. Food Balance Sheets. http://faostat3.fao.org/download/FB/FBS/E. Accessed May 2014.

58. Monsen ER. Iron nutrition and absorption: dietary factors which impact iron bioavailability. J Am Diet Assoc. 1988;88:786-90. 
59. Verhoef H, West CE, Ndeto P, Burema J, Beguin Y, Kok FJ. Serum transferrin receptor concentration indicates increased erythropoiesis in Kenyan children with asymptomatic malaria. Am J Clin Nutr. 2001;74:767-75.

60. Glinz D, Hurrell RF, Righetti AA, Zeder C, Adiossan LG, Tjalsma H, et al. In Ivorian school-age children, infection with hookworm does not reduce dietary iron absorption or systemic iron utilization, whereas afebrile Plasmodium falciparum infection reduces iron absorption by half. Am J Clin Nutr. 2015;101:462-70. doi:10.3945/ajcn.114.090175.

61. National Statistics Office of the Republic of Malawi. Malawi Demographic and Health Survey 2010. NSO, Zomba, Malawi, 2011. http://dhsprogram. com/pubs/pdf/FR247/FR247.pdf. Accessed December 2013.

62. Iodine Global Network. Global iodine nutrition scorecard for 2014. IGN, Zurich, 2014. http://ign.org/cm_data/Scorecard_IGN_website_02_03_2015. pdf. Accessed January 2015.

63. World Health Organization. lodine status worldwide. In: de Benoist B, Andersson M, Egli I, Takkouche B, Allen H, editors. WHO Global Database on lodine Deficiency. Geneva: WHO; 2004.

64. Mdebwe HJ, Banda TW. A survey report on the trend of prevalence of goitre in junior primary school pupils and coverage of iodized salt at household level in seven districts in northern and central regions of Malawi. Lilongwe, Malawi: Ministry of Health and Population; 1996.

65. Zimmermann MB. Flawed approach in the GBD 2010 for iodine deficiency compromises its findings. IDD newsletter, February 2013. http://ign.org/ newsletter/idd_feb13_global_burden_of_disease.pdf. Accessed February 2015.

66. Kalimbira AA, Chilima DM, Mtimuni BM, Mvula N. Knowledge and practices related to use of iodised salt among rural Malawian households. J Agric Environ Sci Technol. 2005:3:73-82.

67. Bohn T, Davidsson L, Walczyk T, Hurrell RF. Phytic acid added to whitewheat bread inhibits fractional apparent magnesium absorption in humans. Am J Clin Nutr. 2004;79:418-23.

68. Fredlund $K$, Isaksson M, Rossander-Hulthén L, Almgren A, Sandberg AS Absorption of zinc and retention of calcium: Dose-dependent inhibition by phytate. J Trace Elem Med Bio. 2006:20:49-57. doi:10.1016/j.jtemb.2006.01.003.

69. Joy EJM, Stein AJ, Young SD, Ander EL, Watts MJ, Broadley MR. Zincenriched fertilisers as a potential public health intervention in Africa. Plant Soil. 2015;389:1-24. doi:10.1007/s11104-015-2430-8.

70. World Health Organization and Food and Agriculture Organization of the United Nations. Diet, nutrition and the prevention of chronic diseases. Report of a Joint WHO/FAO Expert Consultation. Geneva: WHO; 2003.

71. World Health Organization. Reducing salt intake in populations: Report of a WHO forum and technical meeting, 5-7 October 2007, Paris, France. Geneva: WHO; 2007

72. Chilimba ADC, Young SD, Black CR, Meacham MC, Lammel J, Broadley MR. Agronomic biofortification of maize with selenium (Se) in Malawi. Field Crop Res. 2012;125:118-28. doi:10.1016/j.fcr.2011.08.014

73. Chilimba ADC, Young SD, Black CR, Meacham MC, Lammel J, Broadley MR. Assessing residual availability of selenium applied to maize crops in Malawi. Field Crop Res. 2012;134:11-8. doi:10.1016/j.fcr.2012.04.010.

74. Chilimba ADC, Young SD, Joy EJM. Agronomic biofortification of maize, soybean and groundnut with selenium in intercropping and sole cropping systems. Afr J Agric Res. 2014;9:3620-6. doi:10.5897/AJAR2014.8978.

75. Alfthan $G$, Eurola $M$, Ekholm $P$, Venäläinen $E-R$, Root $T$, Korkalainen $K$, et al. Effects of nationwide addition of selenium to fertilizers on foods, and animal and human health in Finland: From deficiency to optimal selenium status of the population. J Trace Elem Med Bio. 2015;31:142-7. doi:10.1016/j.jtemb.2014.04.009.

76. Broadley MR, Alcock J, Alford J, Cartwright P, Foot I, Fairweather-Tait SJ, et al. Selenium biofortification of high-yielding winter wheat (Triticum aestivum L.) by liquid or granular Se fertilisation. Plant Soil. 2010;332:5-18. doi:10. 1007/s11104-009-0234-4

77. White PJ, Broadley MR. Biofortification of crops with seven mineral elements often lacking in human diets - iron, zinc, copper, calcium, magnesium, selenium and iodine. New Phytol. 2009;182:49-84. doi:10.1111/j.1469-8137.2008.02738.x.

78. Fiedler JL, Lividini K, Zulu R, Kabaghe G, Tehinse J, Bermudez Ol. Identifying Zambia's industrial fortification options: Toward overcoming the food and nutrition information gap-induced impasse. Food Nutr Bull. 2013;34:480-500.

79. Lyons GH, Stangoulis JCR, Graham RD. High selenium wheat: biofortification for better health. Nutr Res Rev. 2003;16:45-60.
80. International Fertilizer Development Center Malawi fertilizer assessment. Alabama, U.S.A: IFDC. 2013https://ifdcorg.files.wordpress.com/2015/04/ malawi-fertilizer-assessment.pdf. Accessed June 2014.

81. Broadley MR, White PJ, Bryson RJ, Meacham MC, Bowen HC, Johnson SE, et al. Biofortification of UK food crops with selenium. Proc Nutr Soc. 2006;65:169-81. doi:10.1079/PNS2006490.

82. Fiedler JL. Towards overcoming the food consumption information gap: Strengthening household consumption and expenditures surveys for food and nutrition policymaking. Global Food Secur. 2013;2:56-63. doi:10.1016/j.gfs.2012.09.002.

83. Archer E, Hand GA, Blair SN. Validity of U.S. nutritional surveillance: National Health and Nutrition Examination Survey caloric energy intake data, 1971-2010. PLoS One. 2013;8, e76632. doi:10.1371/journal.pone.0076632.

84. Rennie KL, Coward A, Jebb SA. Estimating underreporting of energy intake in dietary surveys using an individualised method. Br J Nutr. 2007:97:1169-76. doi:10.1017/S0007114507433086.

85. Bentley ME, Cornelli AL, Piwoz E, Moses A, Nkhoma J, Tohill BC, et al. Perceptions of the role of maternal nutrition in the HIV-positive breastfeeding women in Malawi. J Nutr. 2005;135:945-9.

86. Bouis HE, Eozenou P, Rahman A. Food prices, household income, and resource allocation: Socioeconomic perspectives on their effects on dietary quality and nutritional status. Food Nutr Bull. 2011;32:S14-23.

87. Fordyce FM, Johnson CC, Navaratna URB, Appleton JD, Dissanayake CB. Selenium and iodine in soil, rice and drinking water in relation to endemic goitre in Sri Lanka. Sci Total Environ. 2000;263:127-41. doi:10.1016/S0048-9697(00)00684-7.

88. Voutchkova DD, Ernstsen V, Hansen B, Sørensen BL, Zhang C, Kristiansen SM. Assessment of spatial variation in drinking water iodine and its implications for dietary intake: A new conceptual model for Denmark. Sci Total Environ. 2014;493:432-44. doi:10.1016/j.scitotenv.2014.06.008.

\section{Submit your next manuscript to BioMed Central and we will help you at every step:}

- We accept pre-submission inquiries

- Our selector tool helps you to find the most relevant journal

- We provide round the clock customer support

- Convenient online submission

- Thorough peer review

- Inclusion in PubMed and all major indexing services

- Maximum visibility for your research

Submit your manuscript at www.biomedcentral.com/submit
) Biomed Central 